See discussions, stats, and author profiles for this publication at: https://www.researchgate.net/publication/224203022

\title{
An Evaluation of the ALOS PALSAR L-Band Backscatter-Above Ground Biomass Relationship Queensland, Australia: Impacts of Surface Moisture Condition and Vegetation Structure
}

Article in IEEE Journal of Selected Topics in Applied Earth Observations and Remote Sensing • January 2011

DOI: 10.1109/JSTARS.2010.2086436 · Source: IEEE Xplore

CITATIONS

245

16 authors, including:

Richard Lucas

Aberystwyth University

276 PUBLICATIONS 10,410 CITATIONS

SEE PROFILE

Arnon Accad

Queensland Herbarium

53 PUBLICATIONS 764 CITATIONS

SEE PROFILE

Some of the authors of this publication are also working on these related projects:

Project Status and trends of the Wet Tropics View project

Coseismic deformation of the Maule, Chile earthquake View project
READS

955

John Armston

University of Maryland, College Park

135 PUBLICATIONS 4,623 CITATIONS

SEE PROFILE

Joao Carreiras

The University of Sheffield

76 PUBLICATIONS 2,319 CITATIONS

SEE PROFILE 


\title{
An Evaluation of the ALOS PALSAR L-Band Backscatter-Above Ground Biomass Relationship Queensland, Australia: Impacts of Surface Moisture Condition and Vegetation Structure
}

\author{
Richard Lucas, John Armston, Russell Fairfax, Rod Fensham, Arnon Accad, Joao Carreiras, Jack Kelley, \\ Peter Bunting, Dan Clewley, Steven Bray, Dan Metcalfe, John Dwyer, Michiala Bowen, Teresa Eyre, \\ Melinda Laidlaw, and Masanobu Shimada, Senior Member, IEEE
}

\begin{abstract}
Focusing on woody vegetation in Queensland, Australia, the study aimed to establish whether the relationship between Advanced Land Observing Satellite (ALOS) Phased Array L-band SAR (PALSAR) HH and HV backscattering coefficients and above ground biomass (AGB) was consistent within and between structural formations (forests, woodlands and open woodlands, including scrub). Across these formations, 2781 plot-based measurements (from 1139 sites) of tree diameters by species were collated, from which AGB was estimated using generic allometric equations. For Queensland, PALSAR fine beam dual (FBD) $50 \mathrm{~m}$ strip data for 2007 were provided through the Japanese Space Exploration Agency's (JAXA) Kyoto and Carbon $(\mathrm{K} \& \mathrm{C})$ Initiative, with up to 3 acquisitions available for each Reference System for Planning (RSP) paths. When individual strips acquired over Queensland were combined, 'banding' was evident within the resulting mosaics, with this attributed to enhanced L-band backscatter following rainfall events in some areas. Reference to Advanced Microwave Scanning Radiometer-EOS (AMSR-E) data indicated that strips with enhanced L-band backscatter corresponded to areas with increased effective vegetation water
\end{abstract}

Manuscript received November 09, 2009; revised July 11, 2010; accepted September 09, 2010. Date of current version December 15, 2010.

R. Lucas, P. Bunting, and D. Clewley are with the Institute of Geography and Earth Sciences, Aberystwyth University, Aberystwyth, Ceredigion, Wales, SY23 3DB, Wales, U.K. (e-mail: rml@aber.ac.uk).

J. Armston is with the Queensland Department of Environment and Resource Management, Brisbane, Australia. He is also with the Centre for Spatial Environmental Research, School of Geography, Planning and Environmental Management, The University of Queensland, Australia.

R. Fairfax, R. Fensham, A. Accad, J. Kelley, M. Laidlaw, and T. Eyre are with the Queensland Department of Environment and Resource Management, Brisbane, Australia.

J. Carreiras is with the Geo-information for Development Unit, Department of Natural Sciences, Tropical Research Institute (IICT), 1300-319 Lisboa, Portugal.

S. Bray is with the Queensland Primary Industries and Fisheries, Department of Employment, Economic Development and Innovation, Rockhampton, Queensland, Australia.

D. Metcalfe is with CSIRO, Atherton, Queensland, Australia.

J. Dwyer is with the The Ecology Centre, School of Integrative Biology, Faculty of Biological and Chemical Sciences, The University of Queensland, St. Lucia Campus, Brisbane, Queensland, Australia.

M. Bowen is with the Centre for Spatial Environmental Research, School of Geography, Planning and Environmental Management, The University of Queensland, Australia.

M. Shimada is with the Japan Aerospace Exploration Agency (JAXA), Earth Observation Research Center (EORC), Tsukuba, Ibaraki, Japan, 305-8505.

Color versions of one or more of the figures in this paper are available online at http://ieeexplore.ieee.org.

Digital Object Identifier 10.1109/JSTARS.2010.2086436 content $\left(\mathrm{kg} \mathrm{m}^{-2}\right)$ and, to a lesser extent, soil moisture $\left(\mathrm{g} \mathrm{cm}^{-3}\right)$. Regardless of moisture conditions, L-band HV topographically normalized backscattering intensities backscatter $\left(\sigma_{f}^{\circ}\right)$ increased asymptotically with AGB, with the saturation level being greatest for forests and least for open woodlands. However, under conditions of relative maximum surface moisture, L-band $\mathrm{HV}$ and $\mathrm{HH}$ $\sigma_{f}^{\circ}$ was enhanced by as much as 2.5 and $4.0 \mathrm{~dB}$ respectively, particularly for forests of lower AGB, with this resulting in an overall reduction in dynamic range. The saturation level also reduced at L-band HH for forests and woodlands but remained similar for open woodlands. Differences in the rate of increase in both $L$-band HH and HV $\sigma_{f}^{\circ}$ with AGB were observed between forests and the woodland categories (for both relatively wet and dry conditions) with these attributed, in part, to differences in the size class distribution and stem density between non-remnant (secondary) forests and remnant woodlands of lower AGB. The study concludes that PALSAR data acquired when surface moisture and rainfall are minimal allow better estimation of the AGB of woody vegetation and that retrieval algorithms ideally need to consider differences in surface moisture conditions and vegetation structure.

Index Terms-Above-ground biomass, ALOS PALSAR, Australia, forests, K\&C initiative, Queensland.

\section{INTRODUCTION}

\section{A. Requirement for Biomass Information}

$\mathbf{K}$ NOWLEDGE of the spatial distribution and amounts of carbon stored within woody vegetation is remaining an important requirement for national and international governments and organizations charged with reducing greenhouse gases emissions [1]. For this purpose, baseline maps of biomass contained within the world's forests and woodlands are required as these provide increased knowledge of a) carbon losses and gains associated with vegetation clearance or regeneration, $b$ ) the restoration potential of vegetation (e.g., based on biomass estimates for mature (remnant) forests occurring in proximity or within the same environmental envelope), and c) vegetation carbon dynamics if used as input to carbon models, and particularly those associated with national or regional carbon accounting systems.

A component of increasing knowledge of carbon stored in vegetation is the advancement of methods for spatially retrieving and reducing uncertainty in the estimates of biomass 
[2] on a routine basis and at a global level. Such methods can contribute to international efforts to conserve and restore vegetation for mitigating the effects of climate change (e.g., the Kyoto Protocol and Reducing Emissions from Deforestation and Degradation (REDD) initiative).

Many studies have seen a role for lower frequency $\mathrm{L}(\sim 1.25$ $\mathrm{GHz})$ and P-band $(\sim 0.45 \mathrm{GHz})$ Synthetic Aperture Radar (SAR) for retrieving the above ground biomass (AGB) of forests (e.g., [3]-[7]). However, generalized algorithms for the retrieval of AGB from SAR intensity data, across a range of structural formations and at a regional or global level have not been forthcoming for several reasons:

a) Many studies have reported saturation of SAR data when AGB exceeds approximately $60-100 \mathrm{Mg} \mathrm{ha}^{-1}$ and 100-150 Mg ha ${ }^{-1}$ for L-and P-band respectively, although reported levels vary considerably [4]. This has led to the perception that SAR data are limited for retrieval, particularly in many higher biomass forests.

b) Many algorithms developed have not been evaluated more widely as studies have used narrow swath width airborne SAR data acquired over localized areas.

c) For regional mapping, L-band SAR data have only been available (often intermittently) from the Japanese Earth Resources Satellite (JERS-1) SAR and Shuttle Imaging Radar (SIR) missions of the 1990s. Studies using spaceborne SAR data have typically focused on one or several scenes acquired under varying meteorological conditions and vegetation states.

d) Variability in relationships between SAR backscatter and AGB has been observed as a function of sensor parameters, including incidence angle [8] and environmental factors (e.g., freeze-thaw cycles; [9]), which has compromised retrieval.

e) The majority of studies have focused on a single biome (e.g., temperate forests) and often a specific forest type (e.g., even-aged monospecific plantations, semi-natural forests) or structural formation (e.g., [10], [11]), although studies are increasingly focusing on more complex and diverse 'natural' forests.

The collation of relationships between SAR intensity data and AGB for a range of forest biomes can allow variations within and between structural formations to be evaluated. However, consistency issues arise between SAR datasets (in terms of calibration, accounting for environmental variability) and the amount, distribution, time stamp and inter-comparability of the field data sets used to calibrate and validate algorithms. As a result, transferability of algorithms within and between different forest structures is limited and does not yet allow reliable and consistent retrieval of AGB. For this reason, alternative approaches (e.g., SAR interferometry, polarimetric interferometry or the inclusion of LiDAR or other environmental data) have been considered, with investigations continuing (e.g., [12]-[14]).

In 2006, the Japanese Space Exploration Agency (JAXA) launched the Advanced Land Observing Satellite (ALOS) Phased Arrayed L-band SAR (PALSAR) and the JAXA Kyoto and Carbon (K\&C) Initiative aimed to advance and demonstrate the use of these data for regional applications. As part of the $\mathrm{K} \& \mathrm{C}, 50 \mathrm{~m}$ fine-beam dual polarization (FBD) strip data were provided for northern Australia and presented a unique opportunity to better examine the variability in the relationship between SAR intensity data and the AGB of woody vegetation. As a regional study area, the State of Queensland was ideally suited because large environmental gradients, anthropogenic and natural disturbance regimes (e.g., deforestation, droughts, fire and regrowth) have resulted in a wide range of structures and AGB. The primary aim of the research was therefore to establish the consistency of relationships between L-band $\mathrm{HH}$ and HV backscatter and field-based measures of AGB within and between structural formations, focusing specifically on the broad classes of forests, woodlands and open woodlands. L-band SAR backscatter is also influenced by moisture on and contained within the vegetation and soil (herein referred to as surface moisture) [15]. Therefore, a secondary aim was to assess the influence of surface moisture on the relationship between L-band backscatter and the AGB of woody vegetation.

The paper is structured as follows. Section II provides a brief description of the physical environment and vegetation (including classification schemes) of Queensland. Sections III outlines the ALOS PALSAR and field (plot) data used for the study. Section IV describes the allometric equations used for estimating AGB from tree size and extraction of ALOS PALSAR data from plot locations. Section $V$ examines the relationships observed between L-band SAR and AGB as a function of polarization, structural formation and surface moisture content. Section VI discusses the reasons for differences observed in the relationships and outlines the significance and implications of the results for regional to global mapping of forest biomass from L-band SAR data. Conclusions, recommendations and future work are given in Section VII.

\section{STUDY AREA}

\section{A. Vegetation in Queensland: Mapping and Monitoring}

The State of Queensland $\left(\sim 1,730,000 \mathrm{~km}^{2}=173\right.$ million ha) is located between $\sim 10^{\circ}$ and $29^{\circ} \mathrm{S}$ and $\sim 137^{\circ}$ and $154^{\circ} \mathrm{E}$ (Fig. 1). The large latitudinal and longitudinal extent results in significant climatic variability and gradients extending from the eastern coastal areas to the western interior. Such variability, together with a diversity of soils and geological types, results in a wide range of vegetation types including desert scrub, grasslands, wooded savannas and tropical rainforests. A detailed classification of vegetation has been undertaken through the Queensland Herbarium Regional Ecosystems (RE) mapping, which is based on field information and aerial photograph interpretation [16]. Descriptions and illustrations of ecosystems can be found in [17]. A broader classification is based on the scheme of [16] (modified from [18]) which assigns vegetation to structural formations according to foliage projected cover (FPC) and canopy height. Forests (open and closed), woodlands and open woodlands are defined as supporting a FPC of $>30 \%$, $10-30 \%$ and $<10 \%$ respectively [19]. The distribution of these broad classes is given in Fig. 1, which is a collage of best available structural mapping.

Across the state, woody vegetation exists in varying stages of degradation and regeneration and is defined as non-remnant 


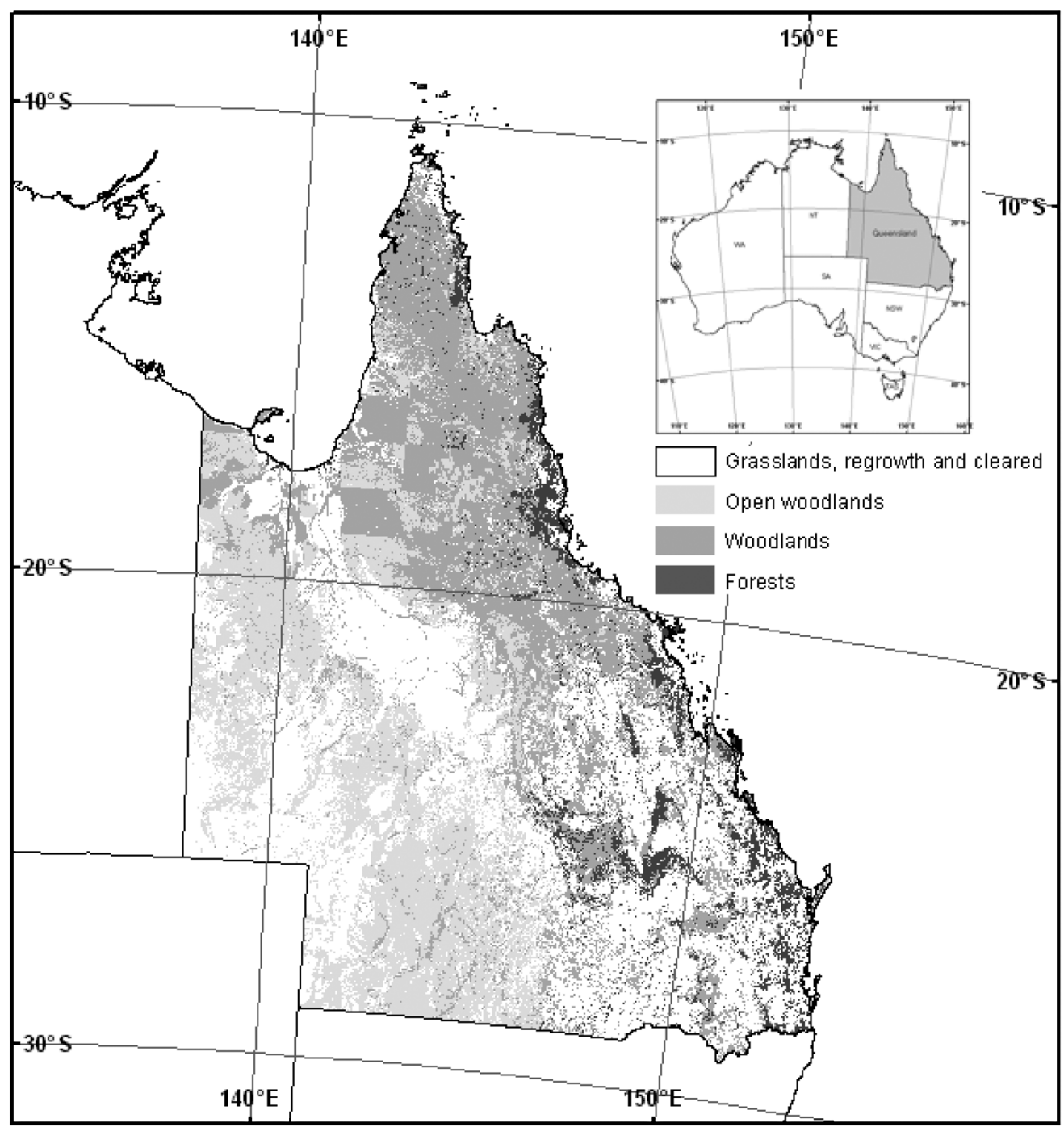

Fig. 1. The location of the state of Queensland, Australia, and distribution of forests, woodlands and open woodlands.

where there is evidence of prior disturbance through mechanical or chemical means (e.g., logging, clearing, poisoning), with this obtained through interpretation of satellite imagery, historical aerial photography or field survey. Woody vegetation is defined as remnant and mapped as such where the dominant canopy has greater than $70 \%$ of the height and $50 \%$ of the cover relative to the undisturbed height and cover of that stratum and is dominated by species characteristic of undisturbed vegetation. Natural events (e.g., fires) and processes (e.g., drought, flooding) also lead to variability in the structure of woody vegetation. Change in remnant ecosystems and vegetation in Queensland are reported in [20].

\section{B. Distribution of AGB Within Queensland}

Several regional estimates of AGB have been generated for Queensland, either as part of a global or national effort or specifically for the State. These have been based on:

a) Associations between ecosystems or broad vegetation types and estimates of carbon in live vegetation (globally [21], for Australia [22]), b) Empirical relationships with coarse $(>1 \mathrm{~km})$ spatial resolution satellite sensor data (for Australia [24]).

c) Relationships between Landsat-derived FPC and basal area and then AGB (for Queensland [23]).

These and more locally-based studies observe that, for remnant vegetation, the highest density of AGB is generally associated with the coastal tall closed forests, which include the subtropical and tropical rainforests in the Wet Tropics of Far North Queensland and higher mountain areas along the east coast. Estimates of AGB reported here often exceed $400 \mathrm{Mg} \mathrm{ha}^{-1}$ and can be greater than $1000 \mathrm{Mg} \mathrm{ha}^{-1}$ [25]. The AGB of woodlands is variable but most support an AGB of $<150 \mathrm{Mg} \mathrm{ha}^{-1}$ [26], [27] and AGB densities generally decline with increasing aridity although this is likely to be impacted by soil type, position in the landscape and past disturbance [28].

\section{DATA}

\section{A. ALOS PALSAR Data}

For Queensland, dual polarization ALOS PALSAR L-band $\mathrm{HH}$ and HV $50 \mathrm{~m}$ strip data for 2007 (PALSAR Reference System for Planning (RSP) \# 359 to 390) were provided as part 
of the $\mathrm{K} \& \mathrm{C}$ Initiative. All data were acquired in fine beam dual mode at a viewing angle of $34.4^{\circ}$ and delivered in single-look complex (SLC) as the normalized backscattering coefficient (sigma0; $\sigma^{\circ}$ ) in slant-range geometry by JAXA. The across track swath width approximated $70 \mathrm{~km}$. For each RSP and in 2007 , up to three strips were acquired over Queensland during the observation cycle [29].

The SAR data were processed using GAMMA SAR processing [30], [31] and in-house software. Following radiometric calibration using updated JAXA calibration factors [32], geocoding of the strip data was undertaken within the Gamma Differential Interferometry and Geocoding (DIFF \& GEO) modules and involved the use of a look-up table to transform the SAR data from the slant-range/azimuth geometry to map projection geometry. The geocoding involved initial determination and then refinement of the geometric transformation and subsequent resampling of the image(s) from radar coordinates to map geometry. For geocoded terrain corrected (GTC) products, the initial determination of the geometric transformation was based on orbital state vectors and used a $30 \mathrm{~m}$ Digital Elevation Model (DEM) provided by the Shuttle Radar Topography Mission (SRTM) [33], [34]. Refinement of the transformation is typically undertaken by establishing offsets between the actual SAR image and one simulated from the SRTM-derived DEM (transformed to radar geometry) through an automated cross-correlation analysis. This refinement is generally successful over hilly and mountainous areas. However, as much of Queensland has very little topographic relief, particularly in the interior, there were often insufficient features for cross-correlation. For this reason, refinement was undertaken based on a regional Landsat Enhanced Thematic Mapper (ETM+) panchromatic mosaic as more features could be used to support determination of the geometric transformation. Finally, the strip data were transformed to a UTM projection for zones 54, 55 and 56 using a look-up table. Geocoding errors were typically less than $50 \mathrm{~m}$. As the Landsat panchromatic data were pivotal in the orthorectification of the ALOS PALSAR data, a high level of co-registration ( $<1$ pixel) with statewide datasets, including land clearing and RE mapping as well as Landsat-derived foliage projected cover (FPC) mosaics, was achieved.

Radar backscatter varies across a scene because of differences in pixel area and local incidence angle caused by changes in surface topography and look angle across the swath. Therefore, to allow comparability of data within and between scenes, topographic and incidence angle correction were undertaken, using the procedures outlined by [33] and [34], providing units of topographically normalized backscattering intensities, $\sigma_{f}^{\text {o }}$, such that

$$
\sigma_{f}^{o}=\sigma^{o} \frac{A_{\text {flat }}}{A_{\text {slope }}}\left(\frac{\cos \theta_{\text {ref }}}{\cos \theta_{\text {loc }}}\right)^{n}
$$

where $A_{\text {slope }}$ is the true pixel area and $A_{\text {flat }}$ the local pixel area for a theoretical flat surface. The local incidence angle and reference angle $\left(39^{\circ}\right.$; the average local incidence angle at mid swath) for the normalisation of the backscatter are represented by $\theta_{l o c}$ and $\theta_{\text {ref }}$ respectively. In the case of vegetation, the exponent $n$ relates to the optical depth but, as with [33], was set to 1 because of the difficulty in obtaining values for the diversity of vegetation structures encountered.

The orthorectification and topographic correction procedures were applied to each individual strip. The resulting archive of orthorectified ground range $\sigma_{f}^{\text {o }}$ strip images (up to three per RSP) was then available to generate $50 \mathrm{~m}$ mosaics of ALOS PALSAR L-band HH and HV data for 2007. However, when strips from some dates were combined, 'banding' was observed within the resulting mosaic which was attributed to enhanced L-band $\sigma_{f}^{\circ}$ following rainfall events over some areas (as determined initially through reference to SILO [35] meteorological data).

\section{B. Rainfall and Soil Moisture}

To better establish the influence of rainfall and surface moisture on the L-band response and the implications for AGB retrieval, the amount of rainfall $(\mathrm{mm})$ on the day of ALOS strip data acquisition was extracted for the area of each RSP from surfaces $\left(0.05^{\circ} \times 0.05^{\circ}\right.$ spatial resolution) interpolated from meteorological station data (SILO). Daily effective vegetation water content $\left(\mathrm{kg} \mathrm{m}^{-2}\right)$ and near surface $(<1 \mathrm{~cm}$ depth) soil moisture $\left(\mathrm{g} \mathrm{cm}^{-3}\right)$ estimates derived from the Aqua Advanced Microwave Scanning Radiometer-EOS (AMSR-E; launched May 2002) were also sourced through the National Snow and Ice Data Center (NSIDC) by CSIRO Land and Water, Canberra. AMSR-E is a passive microwave sensor operating at 6.925 , 10.65 and $18.7 \mathrm{GHz}$ at a nominal spatial resolution of $25 \mathrm{~km}$. Soil moisture estimates are derived using the algorithm of [36], [37] which exploits the polarization ratio of the $10.65 \mathrm{GHz}$ (X-band; $\sim 3 \mathrm{~cm}$ wavelength) brightness temperature of the vertically and horizontally polarized AMSR-E. Variation in this ratio is interpreted as the short-term dynamics in the soil moisture signal. Estimates of soil moisture are most reliable in areas with minimal vegetation. AMSR-E estimates of vegetation water content are not decoupled from the effects of surface roughness because both have the same influence on the polarization ratio used in the retrieval algorithm (Njoku and Chan, 2005). Thus, the estimates are termed effective vegetation water content and are used as a correction factor in the AMSR-E soil moisture retrieval algorithm as well as for the interpretation of the soil moisture estimates. Soil moisture and effective vegetation water content estimates derived from the ascending Aqua passes were used to select ALOS PALSAR strips acquired under relatively dry conditions. Ascending Aqua passes were used because comparison of the AMSR-E data with SILO daily rainfall surfaces suggested greater sensitivity than descending passes to rainfall events and the subsequent retention of surface moisture. These results are not presented for brevity. The use of ascending passes is consistent with other soil moisture research in Australian savanna environments [38]. To balance reducing noise in the data with preserving short-term variability, a 5-day boxcar average filter was applied to the AMSR-E time-series for 2007 prior to extraction. This procedure also ensured there was complete 'daily' spatial coverage for all of Queensland.

\section{Field Data}

Field-based measurements of tree size (all trees $>5 \mathrm{~cm}$ diameter at breast height; dbh) and species type were collated from 19 studies conducted in Queensland (Table I). Most of the 


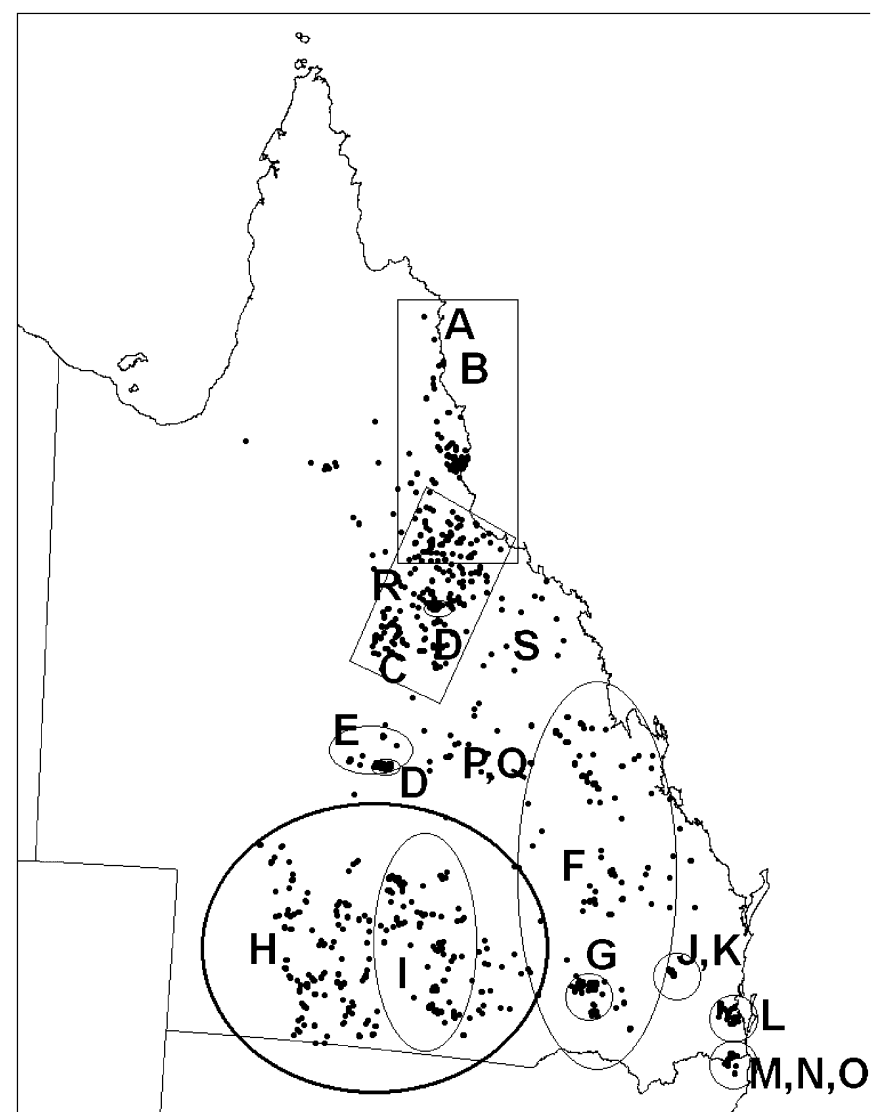

Fig. 2. The location of sites in Queensland with available field-based measurements of tree size. See Table I for more information on the study sites.

data were collected between 2005 and 2009 and over a similar time-frame as the ALOS data acquisitions. However, one study (C) was conducted in 1997 as part of the North Queensland Drought Survey. The plots were widely distributed across Queensland (Fig. 2) and located within a range of ecosystems (e.g., savannas, coastal woodland, sub-tropical and tropical rainforest) and structural formations (open woodland to closed forest).

In total, individual tree measurements from 2781 plot-based measurements (herein, referred to as plots) from 1139 sites were obtained and used to generate a 'biomass library'. For each plot location, a polygon of correct size and orientation was generated using GPS coordinates of the lower centre of the plot and orientation data. In five studies (F, G, H, D and L; Table I; Fig. 2), several plots were established to represent a site in terms of its structure and species composition. With reference to Landsat sensor data and other mapping (e.g., derived from aerial photographs and SPOT HRG data), larger polygons were drawn around clusters of these 'plot' polygons. For these five studies, and where plots were within $50 \mathrm{~m}$ of each other, these larger polygons or the pixels intersecting the plots were used for subsequently extracting ALOS PALSAR data. In several studies (N,B), single plots smaller (e.g., $20 \times 20 \mathrm{~m}$ ) than the $50 \mathrm{~m}$ spatial resolution of the ALOS PALSAR were located within relatively homogeneous contiguous tracts of closed forest, with these often being in mountainous areas. To reduce the impact of misregistration due to poor GPS accuracy under the closed canopy, the dimensions of these plots were extended to $200 \mathrm{~m}$ by $200 \mathrm{~m}$. To investigate the relationships between L-band $\mathrm{HH}$ and $\mathrm{HV} \sigma_{f}^{\mathrm{o}}$ and AGB, data were extracted initally from 2781 plot locations. However, each plot location was individually checked against Landsat reflectance and FPC data and Statewide Landcover and Trees Study (SLATS) woody vegetation clearing histories [59] to ensure that these were contained entirely within a contiguous section of vegetation and that change (e.g., clearing, fire, natural tree death) had not occurred between the dates of acquiring field and ALOS PALSAR data. Where plot locations were affected, these were omitted from further analyses. A number of plot locations were also excluded as they had were located in areas of radar shadow/layover, at the edge of the swath, within strips of vegetation smaller in width than the resolution of the ALOS data, or on the border with another vegetation type. This reduced the number of plots to 1815. A number of individual plots were then aggregated to the site level because they were too close to each other to be considered independent (i.e., the same or adjacent pixels were contributing to the average backscatter values for different sites). The final number of site level observations used for analysis was 1018. Several plots for which data had been collected prior to the ALOS PALSAR data acquisitions were included, such as the 1997 North Queensland Drought Survey. At the time of measurement, all plots associated with this survey were located within remnant vegetation and while some changes were likely [42], the AGB was assumed to remain relatively similar up to the time of ALOS data acquisition.

\section{ANALYSIS}

\section{A. Allometrics for AGB Estimation}

Allometric equations for estimating AGB for a range of Australian tree species were collated from published sources, from which eight were selected for application to the plot data (Table II). Selection was based on the relative behavior of the functions across the likely range of sizes, wood densities [69] and structural forms. Generic forms of equations published by [64] and [26] were used to estimate the AGB of forest/woodlands and rainforest species respectively. For common genera, species-specific allometrics (e.g., [68]) were also considered but similar estimates were obtained as when using generic equations. This was expected given the similarities in the form and wood density of many species (e.g., Eucalyptus and Corymbia). Furthermore, the [26] data were included in the derivation of the [64] generic equations. The equation of [64] predicted slightly higher values of AGB compared to [25]. For palms, an equation generated outside of Australia [66] was used. Some species-specific equations were used for brigalow (Acacia harpophylla), mulga (Acacia aneura) and sandalwood box (Eremophila mitchelli) because of the uniqueness in form of these species. For Xanthorrhoea spp. and cycads, which do not necessarily develop a large height with diameter and have low wood density, the equation of [62] was used. Banksia has a lower height-to-diameter ratio and lower wood density compared to trees with more closed crowns, which was reflected in the lowest predictions of AGB using the equation of [63]. Equations used either diameter at $30 \mathrm{~cm}$ or $130 \mathrm{~cm}$ above ground level as the independent variable. The AGB was estimated for 
TABLE I

SOURCES OF AGB DATA, QUEENSLAND, Australia

\begin{tabular}{|c|c|c|c|c|c|c|}
\hline $\begin{array}{c}\text { Study } \\
\text { (see Fig. 2) }\end{array}$ & No. sites & No. plots & $\begin{array}{l}\text { Typical plot size } \\
\text { (m) }\end{array}$ & Date & Description & Reference \\
\hline A & 1 & 1 & $100 \times 95 \mathrm{~m}$ & 2005 & Forest & [39] \\
\hline B & 99 & 99 & $50 \times 20 \mathrm{~m}$ & $2005-8$ & Rainforest, some Eucalyptus forest & [40] \\
\hline $\mathrm{C}$ & 199 & 199 & $100 \times 20 \mathrm{~m}$ & 1997 & $\begin{array}{l}\text { Eucalyptus woodland } \\
\text { Some Acacia open forest }\end{array}$ & {$[41,42]$} \\
\hline $\mathrm{D}$ & 95 & 760 & Eight $50 \times 8 \mathrm{~m}$ & 2004 & Acacia and eucalyptus dominated & [43] \\
\hline $\mathrm{E}$ & 45 & 45 & $50 \times 20 \mathrm{~m}$ & 2007 & Acacia cambegei woodlands/forest and grasslands & {$[44,45]$} \\
\hline $\mathrm{F}$ & 42 & 270 & Four $50 \times 4 \mathrm{~m}$ & 2007 & $\begin{array}{l}\text { Acacia harpophylla regrowth and remnant woodlands } \\
\text { and forests }\end{array}$ & [46] \\
\hline G & 82 & 164 & Two $2 \times 50 \mathrm{~m}$ & 2005-6 & Acacia harpophylla forests & {$[47]$} \\
\hline $\mathrm{H}$ & 190 & 760 & Four $25 \times 50 \mathrm{~m}$ & $2008-9$ & Acacia and eucalyptus woodlands & {$[48]$} \\
\hline I & 87 & 87 & $50 \times 100 \mathrm{~m}$ & $2008-9$ & Acacia and eucalyptus woodlands regrowth and remnant & [49] \\
\hline $\mathrm{J}$ & 4 & 4 & $100 \times 100 \mathrm{~m}$ & 2003 & rainforest & {$[50]$} \\
\hline $\mathrm{K}$ & 39 & 39 & $50 \times 10 \mathrm{~m}$ & 2003 & Closed forest and grassland & [51] \\
\hline $\mathrm{L}$ & 31 & 128 & Four $40 \times 50 \mathrm{~m}$ & 2009 & Eucalyptus forests & [52] \\
\hline $\mathrm{M}$ & 1 & 1 & $100 \times 100 \mathrm{~m}$ & 2006 & Rainforest & {$[53,55]$} \\
\hline $\mathrm{N}$ & 20 & 20 & $20 \times 20 \mathrm{~m}$ & 2005 & Rainforest & [54] \\
\hline $\mathrm{O}$ & 29 & 29 & $20 \times 20 \mathrm{~m}$ & 2003-4 & Rainforest & [89] \\
\hline $\mathrm{P}$ & 3 & 3 & $100 \times 100 \mathrm{~m}$ & 2004 & Eucalyptus open woodland & [56] \\
\hline Q & 3 & 3 & $100 \times 100 \mathrm{~m}$ & 2008 & Eucalyptus open woodland & [57] \\
\hline $\mathrm{R}$ & 1 & 1 & $300 \times 52 \mathrm{~m}$ & 2004 & Eucalyptus open woodland & [57] \\
\hline $\mathrm{S}$ & 120 & 120 & Five $50-100 \times 2 \mathrm{~m}$ & $2005-8$ & Eucalyptus open woodland & [23] \\
\hline $\mathrm{T}$ & 48 & 48 & $100 \times 100 \mathrm{~m}$ & $2002-4$ & Eucalyptus woodlands & [58] \\
\hline
\end{tabular}

TABLE II

ALLOMETRIC EQUATIONS USED FOR THE ESTIMATION OF AGB

\begin{tabular}{|c|c|c|}
\hline Allometric equation & Application & Source \\
\hline Acacia harpophylla & $\begin{array}{l}\text { Acacia harpophylla, } A \text {. } \\
\text { cambagei, } A \text {. tephrina and allies }\end{array}$ & [58] \\
\hline Eremophila mitchellii & $\begin{array}{l}\text { Semi-arid small trees (high dbh } \\
\text { to height ratio) includes } \\
\text { umbragenous Acacia and other } \\
\text { Eremophila, Petalostigma, } \\
\text { Eythroxylom, Carisssa, Senna } \\
\text { and Bursaria spp. Maytenus } \\
\text { cunninghamii }\end{array}$ & [59] \\
\hline Xanthorrhoea spp. & Xanthorrhoea spp., cycads & [60] \\
\hline Rainforest & $\begin{array}{l}\text { All rainforest, including } \\
\text { mesophyllic semi-arid species } \\
\text { (e.g., Flindersia, conifers } \\
\text { including Callitris spp. }\end{array}$ & {$[25]$} \\
\hline Banksia aemula & $\begin{array}{l}\text { Coastal sclerophyll small trees } \\
\text { (high dbh to height ratio) }\end{array}$ & [61] \\
\hline Forest-woodland & $\begin{array}{l}\text { Eucalyptus, Corymbia, } \\
\text { Angophora, Lophostemon, } \\
\text { Syncarpia, other Acacia, } \\
\text { Casuarina and Melaleuca, } \\
\text { Grevillea and Hakea spp. }\end{array}$ & {$[62]$} \\
\hline Acacia aneura & Acacia aneura and allies & [63] \\
\hline Palms & palms & [64] \\
\hline
\end{tabular}

individual trees, summed and then scaled to units of $\mathrm{Mg} \mathrm{ha}^{-1}$. The AGB of dead trees, which were measured in most plots, was also estimated using correction factors (Table III), with these depending on their health category (determined qualitatively in the field).

As all allometric equations used were of exponential form, the AGB of trees outside of the diameter range for which the equations were derived can be substantially overestimated and the presence of large trees can therefore lead to bias in the estimates. For this reason, equations for Australian trees that encompassed larger individuals in their formulation [26], [68]-[70] were collated and compared with the estimates generated using the equa-
TABLE III

CORRECTION FACTORS FOR THE HEALTH CATEGORY OF A TREE AND THE EXTENT OF Disintegration of a DEAD TREe. THE FACTORS WERE DERIVEd From STUdies ThAT PRESENT ALLOMETRICS FOR DIFFERENT TREe COMPONENTS [58], [59], [61], [65], [66]

\begin{tabular}{|c|c|c|}
\hline Category & Description & $\begin{array}{l}\text { Correction factor } \\
\text { for biomass }(\%)\end{array}$ \\
\hline 0 & $\begin{array}{l}\text { Live (could include major } \\
\text { damage to branches) }\end{array}$ & 100 \\
\hline 1 & $\begin{array}{l}\text { Barely alive (epicormic } \\
\text { growth or almost all crown } \\
\text { dead) }\end{array}$ & 95 \\
\hline 2 & $\begin{array}{l}\text { Recently dead (Bark still } \\
\text { hugging trunk) }\end{array}$ & 90 \\
\hline 3 & $\begin{array}{l}\text { Long dead (Bark present but } \\
\text { not hugging trunk) }\end{array}$ & 90 \\
\hline 4 & $\begin{array}{l}\text { Old dead (Standing but bark } \\
\text { absent) }\end{array}$ & 55 \\
\hline
\end{tabular}

tions in Table II. The forest-woodland equation performed adequately up to $130 \mathrm{~cm}$ but then appeared to over-predict where diameter exceeded $150 \mathrm{~cm}$. Therefore, for some sites containing large trees, the AGB may be over-estimated.

\section{B. Extraction of ALOS PALSAR and Other Data}

For the 1815 locations, L-band HH and HV ( $\sigma_{f}^{\text {o }}$ intensity) were extracted for all strips acquired in 2007 using STARSPAN [73] and then converted to decibels (dB). For each date, effective vegetation water content and soil moisture were derived from AMSR-E and rainfall $(\mathrm{mm})$ from the SILO data [15]. AMSR-E effective vegetation water estimates exhibited a closer correspondence with rainfall events identified in the SILO rainfall surfaces and with areas of enhanced L-band $\sigma_{f}^{\circ}$ (particularly at $\mathrm{HH}$ polarization). In both cases, the correspondence with soil moisture, as estimated from AMSR-E, was less although varied across the State. Pre-clearing RE codes were also extracted and each polygon was associated subsequently with a structural formation (forest, woodland or open woodland; [16]). Within 
these formations, further division into height classes (e.g., tall, medium and low) was not considered for several reasons. First, in the remnant state, few forests in the upper height class support a low AGB and vice versa and so only a partial range of AGB would be considered when formulating relationships with L-band SAR data. Second, regional mapping of height is less certain compared to cover, which can be determined from both aerial photography and optical (e.g., Landsat) sensor data. Polygons associated with field plots were also assigned as remnant or non-remnant.

\section{Empirical Comparisons of Surface Moisture Conditions and Structural Formations}

For Queensland, regional ALOS PALSAR mosaics as well as AMSR-E effective vegetation water content and soil moisture and SILO 5-day rainfall composite mosaics were generated using combinations of data from different dates, including several from 2008 for which some strip data were also available. An overview of the approach to generating the mosaics is given in [15]. For multiple acquisition dates, L-band $\mathrm{HH}$ and $\mathrm{HV} \sigma_{f}^{\mathrm{o}}$ strips data were compared as a function of effective vegetation water content, soil moisture and rainfall, thereby allowing the magnitude of differences in L-band $\sigma_{f}^{\text {o }}$ as a function of these environmental variables to be compared.

Relationships between L-band $\mathrm{HH}$ and $\mathrm{HV} \sigma_{f}^{\mathrm{o}}$ were generated initially using strips acquired under conditions of relatively minimal surface moisture, as determined through reference to effective vegetation water content and, to a lesser extent, soil moisture and rainfall (see Section V). Through this approach, any remaining variation in backscatter was assumed to be related more to differences in surface (e.g., vegetation, ground) structure and roughness. Comparisons were then made with relationships established under relatively wet conditions to investigate the effects of increased surface moisture content. To quantitatively compare the relationships between $\sigma_{f}^{\mathrm{o}}$ and AGB for different structural formations and under these different moisture conditions, the backscatter model of [74] was used where:

$$
\sigma_{f}^{0}(d B)=a+e^{-(b A G B+c)}
$$

$a$ is level at which the relationship becomes asymptotic (in $\mathrm{dB}$ ), $b$ is the gradient of the curve at low biomass and $c$ relates to the nominal backscatter from bare soil. Other published equations (e.g., [8]) were also evaluated but (2) was considered to provide the best fits for all relationships. The objective of the fitting was to simply establish whether relative differences in a defined asymptote (referred to in many studies as the 'saturation' level) occurred between structural formations rather than to establish the level of AGB that might be retrieved by inverting a fitted equation. Scatter in the relationships compromises retrieval and options for AGB estimation are considered in a forthcoming paper. The AGB associated with the saturation level was defined, in this case, from the first derivative and as the lowest AGB where there was a change in $<=0.01 \mathrm{~dB}$ for $1 \mathrm{Mg} \mathrm{ha}^{-1}$ AGB. This method was selected as it could be used consistently for all backscatter models tested. The value of the derivative as a function of AGB can be adjusted but was selected, in this case, for comparative purposes only. Estimates of the dynamic range were also derived, and expressed as the difference between the saturation level in $\mathrm{dB}$ and the $\mathrm{dB}$ predicted by the fitted model for $0 \mathrm{AGB}$. The lowest values of $\sigma_{f}^{\mathrm{o}}$ associated with non-vegetated areas were also established.

\section{RESULTS}

\section{A. Regional ALOS PALSAR Mosaics}

For Queensland, regional ALOS PALSAR mosaics as well as AMSR-E soil moisture and effective vegetation water and SILO rainfall mosaics are shown in Fig. 3. When strips acquired in the 2007 cycle were randomly selected, banding within the ALOS PALSAR mosaic was observed and was attributed to enhanced L-band (particularly $\mathrm{HH}$ ) $\sigma_{f}^{\mathrm{o}}$ in all or part of some strips but not in others. Reference to the AMSR-E and SILO rainfall data indicated that this banding was the result of adjoining strips being acquired under different surface moisture conditions. In partic-

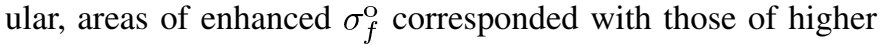
effective vegetation water content and, to varying degrees, rainfall and soil moisture. In one case, rainfall was not recorded on the five days before the ALOS PALSAR acquisition but the effective vegetation water content and soil moisture was slightly higher compared to adjoining strips. The increased L-band $\sigma_{f}^{\mathrm{O}}$ for this strip, which extended from the tip of Cape York southwards, was attributed to the retention of moisture from rainfall events occurring in the days proceeding. By using data acquired in 2007 during relatively dry periods (based primarily on effective vegetation water content), a relatively seamless mosaic was obtained. Even so, some areas (e.g., in south central Queensland) were still associated with elevated surface moisture and rainfall.

The variation in $\sigma_{f}^{\mathrm{o}}$ as a function of moisture conditions is illustrated using RSP 374, which was selected as a range of moisture conditions were observed and for which 2008 strip data were also available. The driest date on which ALOS acquisitions occurred was the 21st July 2007 and similar levels of effective vegetation water content were observed on the $21 \mathrm{st}$ October 2007 and also the 23rd October 2008 resulting in a 1:1

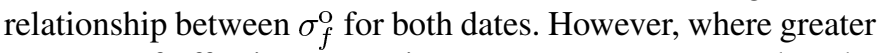
amounts of effective vegetation water content occurred at the time of image acquisition, L-band $\mathrm{HH} \sigma_{f}^{\mathrm{o}}$ was enhanced by up to 4-5 $\mathrm{dB}$ and L-band $\mathrm{HV}$ by a lower amount. This was attributed largely to localized rainfall, which occurred on the 5th September 2007, but also generally wetter conditions across the imaged area (e.g., as observed on the 7th September 2008). The consistency plots support the use of AMSR-E effective vegetation water content in particular for providing a relative indication of surface moisture conditions at the time of the ALOS PALSAR acquisitions and optimizing selection of dates for mosaic generation and data extraction (e.g., for establishing relationships with AGB). Even so, consideration also needs to be given also to soil moisture and rainfall surfaces when generating mosaics.

\section{B. Relationships Between ALOS PALSAR Backscatter and $A G B$}

The distribution of AGB between different structural formations is given in Fig. 5. The AGB of woodlands and open 


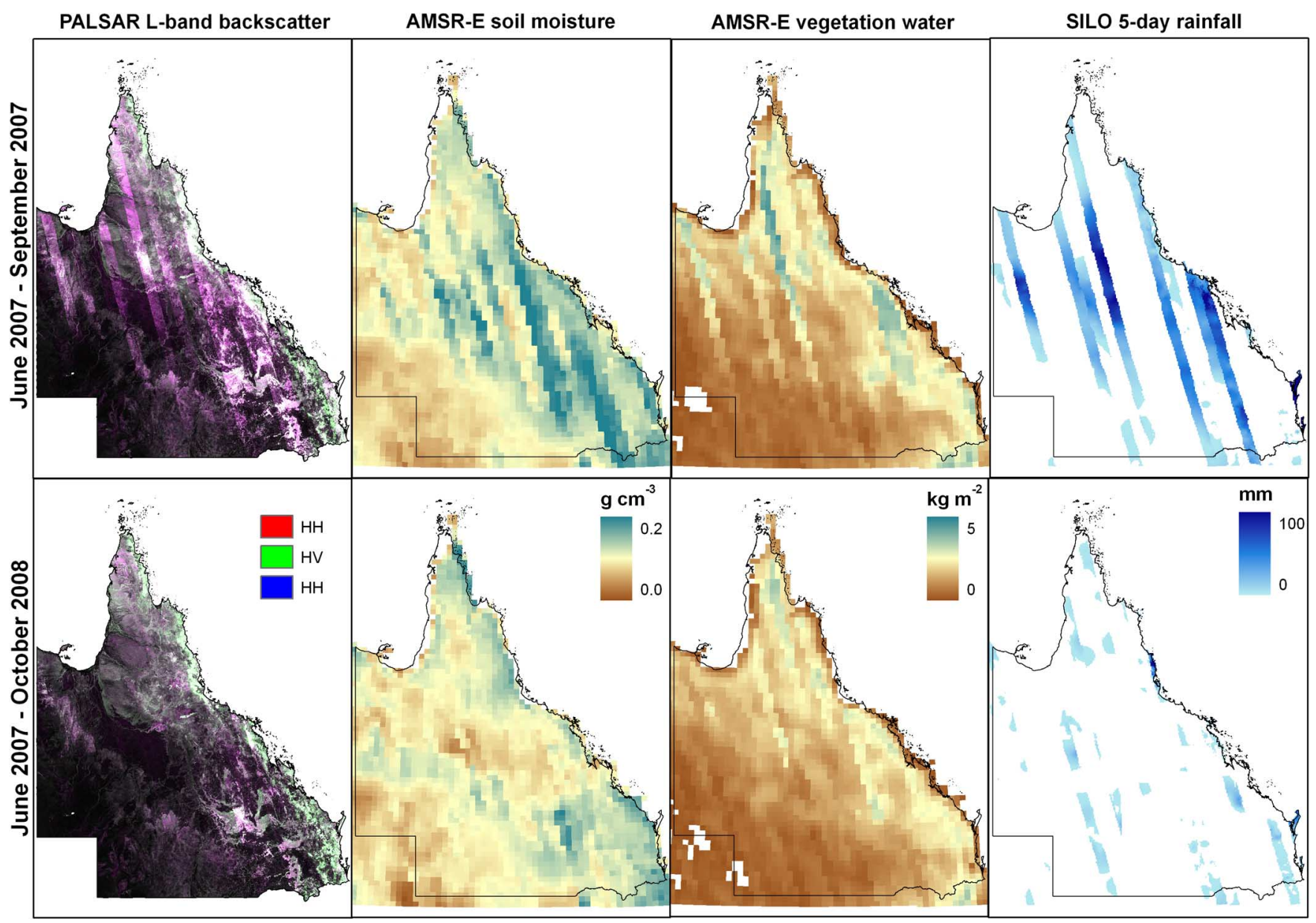

Fig. 3. ALOS PALSAR mosaics generated for Queensland using strips acquired a) on random dates of acquisition in 2007 and b) following periods where surface moisture was at a relative minimum. The soil moisture and effective vegetation water content (derived from AMSR-E) and rainfall over the periods of the ALOS PALSAR acquisitions are also provided (@ JAXA/METI).

(a)

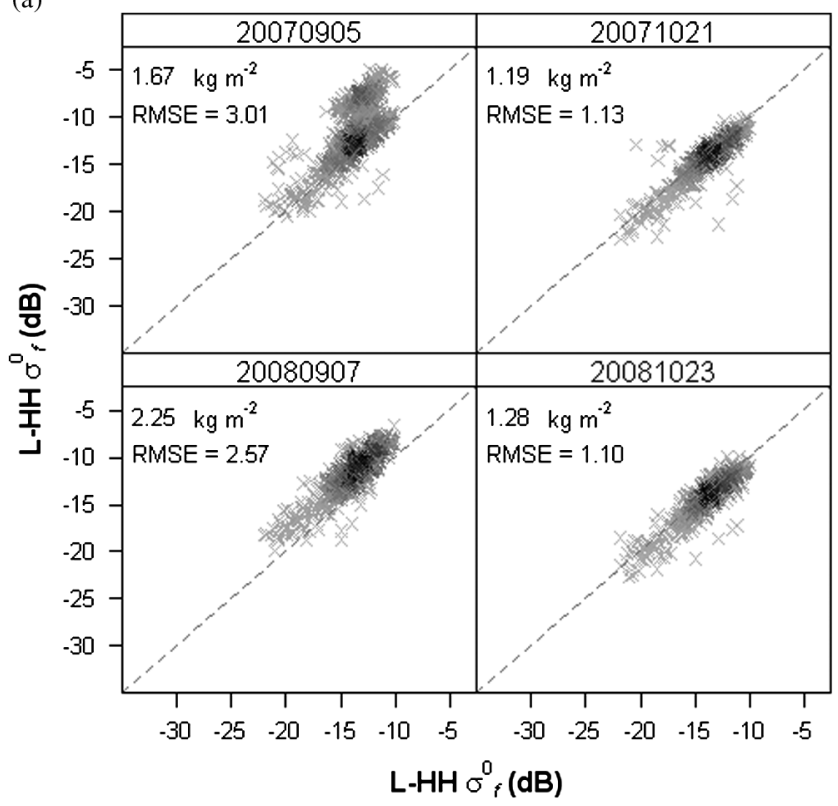

RSP $374-20070721\left(1.11 \mathrm{~kg} \mathrm{~m}^{-2}\right)$ (b)

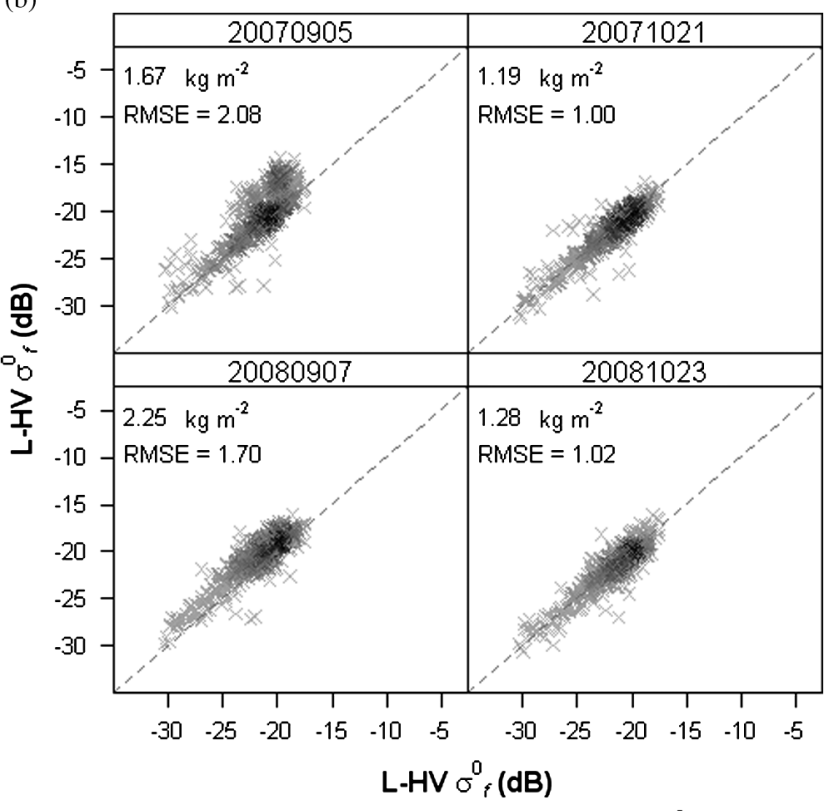

RSP 374 - $20070721\left(1.11 \mathrm{~kg} \mathrm{~m}^{-2}\right)$

Fig. 4. Consistency of a) L-HH and b) L-HV $\sigma_{f}^{\circ}$ for multiple acquisition dates in RSP 374. All data are compared to a reference date (21st July 2007) for which minimum effective vegetation water content was observed, averaged across all AGB plots within RSP 374 . The effective vegetation water content estimates $\left(\mathrm{kg} \mathrm{m}^{-2}\right)$ were derived from AMSR-E ascending orbits (Section III-B). 

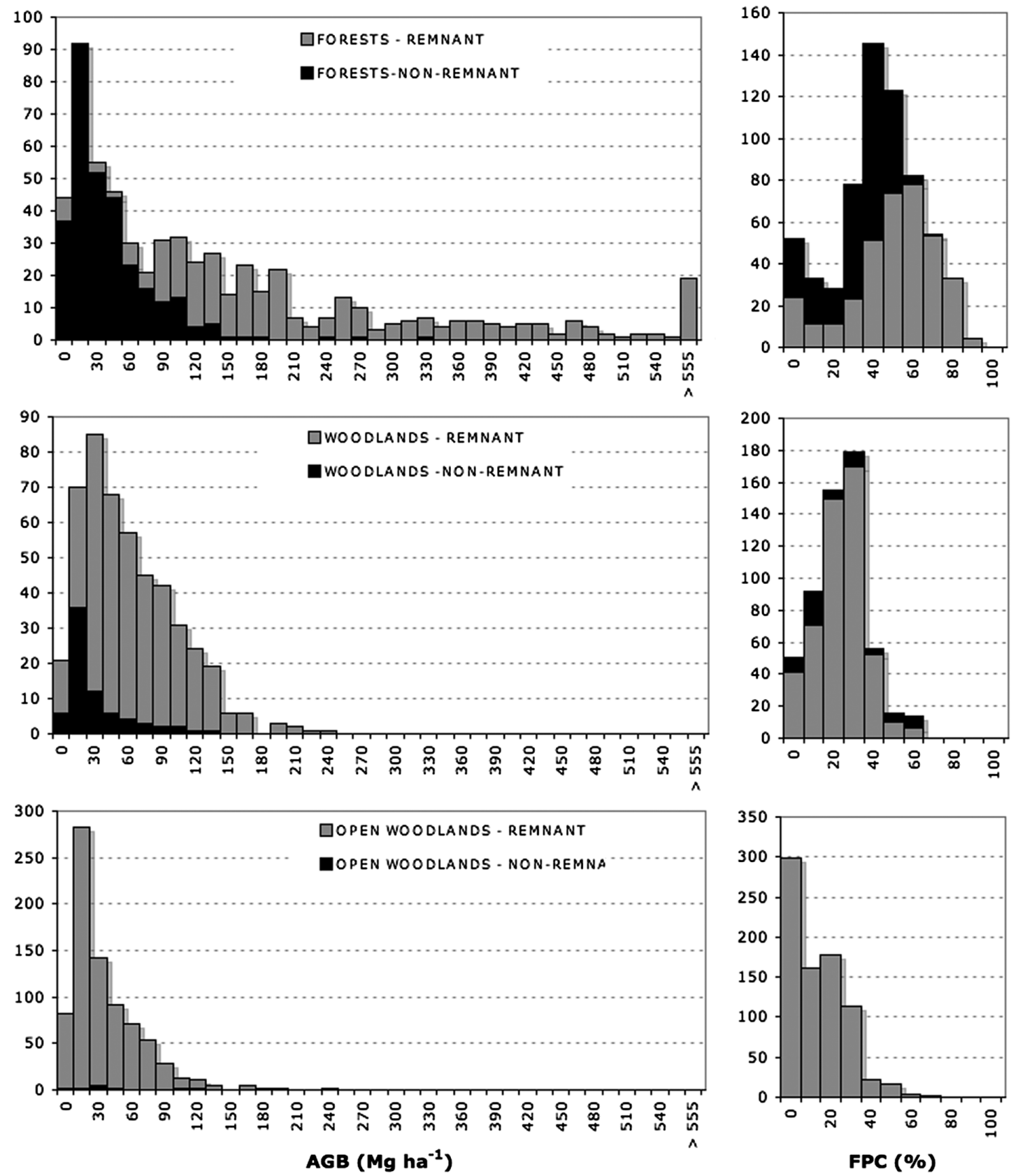

Fig. 5. Frequency of AGB and Landsat-derived FPC by structural formation for both remnant and non-remnant vegetation.

woodlands was up to $250 \mathrm{Mg} \mathrm{ha}^{-1}$, with most being less than $150 \mathrm{Mg} \mathrm{ha}^{-1}$ and $120 \mathrm{Mg} \mathrm{ha}^{-1}$ respectively. Most non-remnant woodlands supported an AGB of $<100 \mathrm{Mg} \mathrm{ha}^{-1}$. Relatively few non-remnant open woodlands were inventoried, but the AGB of these was generally $<40 \mathrm{Mg} \mathrm{ha}^{-1}$. Most forests supported an AGB of $<500 \mathrm{Mg} \mathrm{ha}^{-1}$, although for some, this exceeded 1000 $\mathrm{Mg} \mathrm{ha}^{-1}$. Non-remnant forests generally supported an AGB $<150 \mathrm{Mg} \mathrm{ha}^{-1}$ and were associated largely with regenerating secondary forests. While non-remnant vegetation was identified within all structural formations (and particularly forests), these were often structurally distinct from their mature counterparts. For example, regrowth establishing on cleared agricultural land in the Brigalow Belt Bioregion of eastern central Queensland is typically dominated by Acacia harpophylla which, in the early stages of growth, forms dense stands (often exceeding 10,000 individuals ha ${ }^{-1}$ ). However, in their mature state, stem densities are lower (2000-4000 stems ha ${ }^{-1}$ ) and AGB can approximate $250 \mathrm{Mg} \mathrm{ha}^{-1}$ (live and dead; [75]). An indication of the Foliage Projected Cover (FPC) derived from Landsat sensor data is also provided in Fig. 5 and conveys the greater amount of canopy cover associated with the higher biomass remnant forests compared to non-remnant. For woodlands and open woodlands, differences in FPC between remnant and non-remnant formations were less evident. Illustrations of these structural formations are also given in Fig. 6.

Relationships established between L-band HH and HV and AGB are given in Fig. 7, with these based on extractions of PALSAR data acquired during periods of relative minimum and 
a)

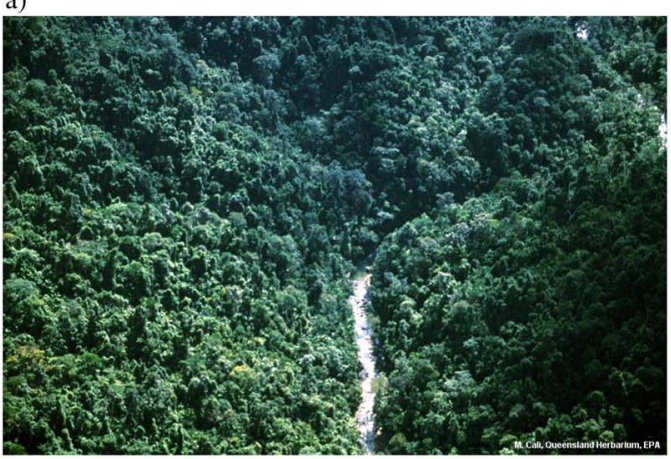

c)

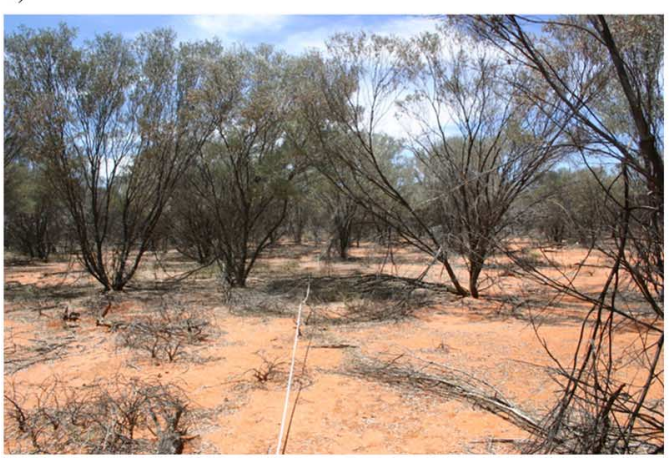

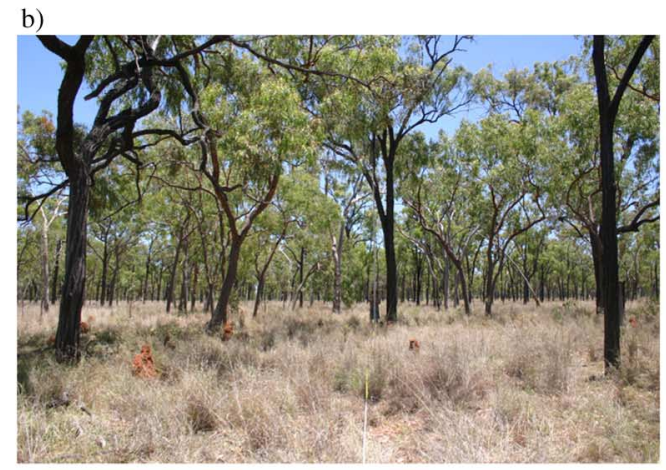

Fig. 6. Examples of (a) closed forest, (b) Eucalyptus spp. woodlands and (c) Acacia aneura (mulga) open woodlands.

maximum effective vegetation water content. For all structural types, $\sigma_{f}^{\mathrm{o}}$ increased asymptotically with AGB from the minimum values associated with areas supporting no woody vegetation. The minimum value was least under drier conditions and for areas associated with open woodlands, and approximated $-27 \mathrm{~dB}$ and $-32 \mathrm{~dB}$ for L-band $\mathrm{HH}$ and $\mathrm{HV}$ respectively. As indicated earlier, the asymptote was defined with respect to a change in $<=0.01 \mathrm{~dB}$ for $1 \mathrm{Mg} \mathrm{ha}^{-1} \mathrm{AGB}$ and is termed hereon in as the saturation level. Here, it is important to re-emphasize that the saturation level does not refer to the level at which AGB can be retrieved but rather is used as a basis for comparing fits established for the different structural formations under different surface moisture conditions.

Using data extracted from strips associated with minimal effective vegetation water content, the dynamic range (from the minimum and maximum associated with bare ground and closed forest respectively) at L-band $\mathrm{HH}$ was $\sim 17 \mathrm{~dB}$ and saturation for forests was observed at approximately $170 \mathrm{Mg} \mathrm{ha}^{-1}$ (Table IV(a)). For woodlands and open woodlands, saturation was observed at $\sim 120$ and $67 \mathrm{Mg} \mathrm{ha}^{-1}$ respectively. By comparison, the equivalent dynamic range at $\mathrm{L}$-band $\mathrm{HV}$ was $\sim 22 \mathrm{~dB}$, suggesting greater potential for resolving a greater number of AGB levels. For forests, L-band HV $\sigma_{f}^{o}$ saturated at $272 \mathrm{Mg} \mathrm{ha}^{-1}$, although a slight upward trend up to $400-500 \mathrm{Mg} \mathrm{ha}^{-1}$ was suggested thereafter. For woodlands and open woodlands, saturation at L-band $\mathrm{HV}$ was observed at comparatively low levels of AGB (139 and $65 \mathrm{Mg} \mathrm{ha}^{-1}$ respectively).

The increases in $\sigma_{f}^{\mathrm{o}}$ with increases in effective vegetation water content led to differences in the saturation level as a function of AGB and/or the degree of scatter observed in the rela- tionships with AGB. At L-band HH and for forests, the AGB at which saturation occurred was reduced to $\sim 97 \mathrm{Mg} \mathrm{ha}^{-1}$, the level of $\sigma_{f}^{\mathrm{o}}$ at the asymptote increased by $\sim 1 \mathrm{~dB}$ to $\sim-9 \mathrm{~dB}$ and the dynamic range (defined using the curve fit) reduced from 5.4 to 2.7. For woodlands and, to a lesser extent, open woodlands, slight decreases in the AGB at which saturation occurred and increases in both the saturation level and RMSE were observed (Table IV(a)). At L-band HV, and for forests, the AGB at which saturation occurred $\left(\sim 270 \mathrm{Mg} \mathrm{ha}^{-1}\right)$, the level of $\sigma_{f}^{\text {o }}$ at the defined asymptote $(\sim-14 \mathrm{~dB})$ and the RMSE $(\sim 2.15 \mathrm{~dB})$ were similar but the dynamic range associated with the line fit was reduced (from 8.3 to $5.9 \mathrm{~dB}$ ). For woodlands and open woodlands, the characteristics of the saturation curve remained similar to those under drier conditions although the RMSE increased slightly, which was attributed to variation in the amounts of moisture in vegetation. Whilst under dry conditions, the upper values of L-band $\mathrm{HH} \sigma_{f}^{\mathrm{o}}$ were not as high as observed for dense closed forests in regions such as Amazonia ( $-6.5 \mathrm{~dB}$ with the standard deviation of $0.5 \mathrm{~dB}$; [76]), those obtained under wetter conditions were more comparable. At the saturation point, L-band $\mathrm{HV} \sigma_{f}^{\circ}$ was as high as $-9.8 \mathrm{~dB}$ in wet and dry conditions and levels were similar to those reported by [33].

The median differences in L-band $\mathrm{HH}$ and $\mathrm{HV} \sigma_{f}^{\mathrm{o}}$ between the maximum and minimum observed effective vegetation water content are given in Fig. 8 at 10 (woodlands and open woodlands) to 20 (forests) $\mathrm{Mg} \mathrm{ha}^{-1}$ bins of AGB. Only bins with greater than three observations are shown. For non-remnant forests supporting an AGB of $<50 \mathrm{Mg} \mathrm{ha}^{-1}$, the median difference in $\sigma_{f}^{\circ}$ was $\sim 3-4 \mathrm{~dB}$ and $2-3 \mathrm{~dB}$ for L-band $\mathrm{HH}$ and $\mathrm{HV}$ respectively. The difference decreased to $\sim 1 \mathrm{~dB}$ for 


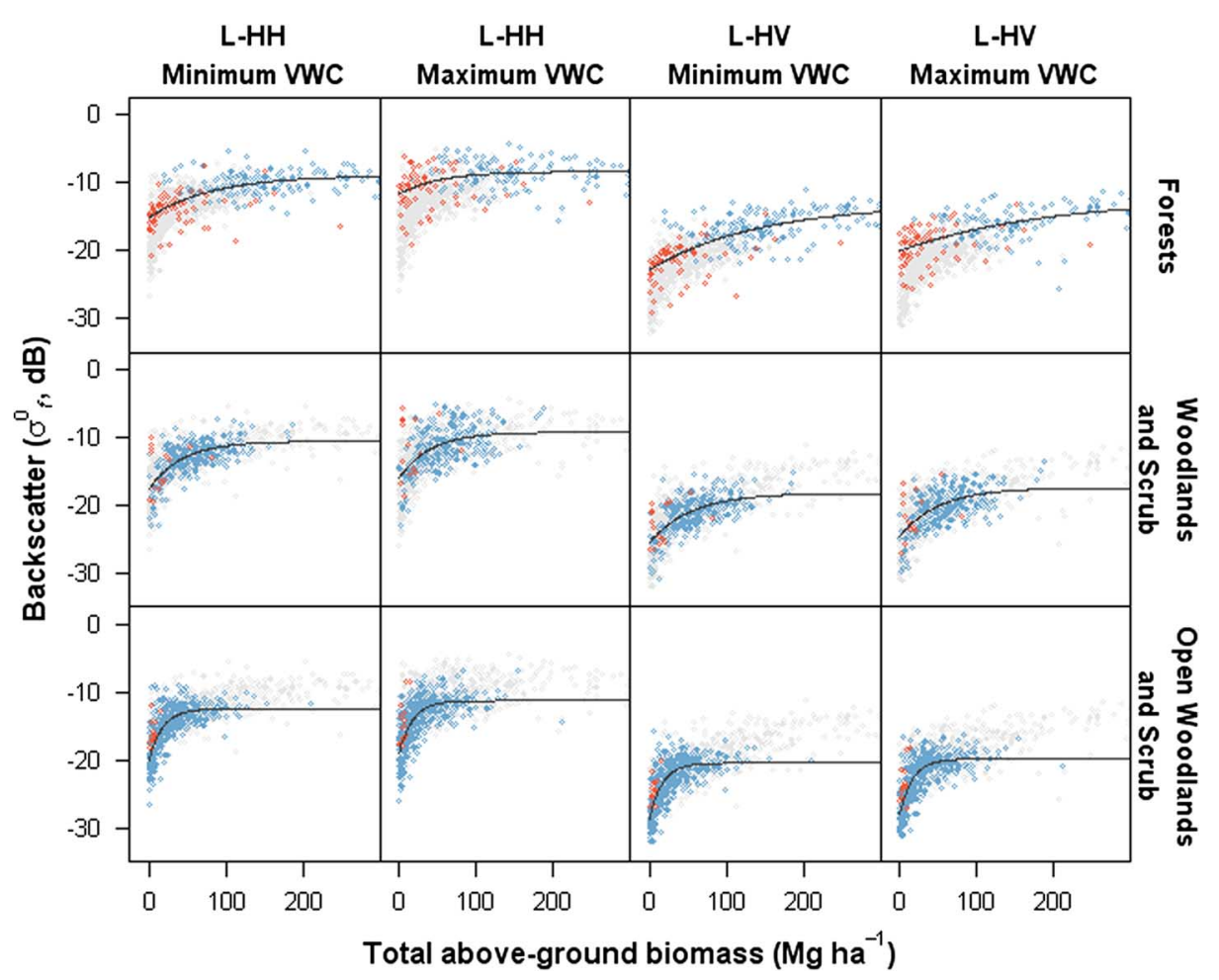

Fig. 7. Relationships between AGB and L- band HH and HV $\sigma_{f}^{\circ}$ for forests, woodlands and open woodlands (up to $300 \mathrm{Mg}^{-1}$ ), based on ALOS PALSAR data acquired during periods of relative minimum and maximum vegetation water content (VWC). Remnant and non-remnant forests are indicated in blue and red respectively. Remaining points in the dataset that were not used to generate the curve fits for forests, woodlands or open woodlands are shown in grey.

most remnant forests with an AGB $>150 \mathrm{Mg} \mathrm{ha}^{-1}$. The impact of vegetation water content was therefore most apparent for the non-remnant forest category, which is predominantly composed of brigalow-dominated forests. A suggested reason for the comparatively greater increase for non-remnant forests with lower AGB was that attenuation by the canopy is least and hence there is a greater likelihood of interaction between the woody vegetation and soil layer. For woodlands and open woodlands with an AGB of $<150 \mathrm{Mg} \mathrm{ha}^{-1}$, an increase of 1-3 $\mathrm{dB}$ was observed, with this being consistently greater for L-band $\mathrm{HH}$.

Differences in $\sigma_{f}^{\text {o }}$ were also evident between remnant and non-remnant vegetation, particularly where the AGB was $<150 \mathrm{Mg} \mathrm{ha}^{-1}$, with non-remnant forests generally supporting higher values of L-band $\mathrm{HH}$ and $\mathrm{HV} \sigma_{f}^{\mathrm{o}}$ (by several $\mathrm{dB}$ ) compared to remnant woodland categories of similar AGB (Fig. 9). For forests, remnant vegetation is generally associated with mature stands. Hence, unless disturbance (e.g., through cyclone damage) has occurred, extensive stands of naturally occurring forests of lower AGB are uncommon. Therefore, for many remnant forests (e.g., in the Wet Tropics of far north Queensland), AGB was consistently high (e.g., $>150 \mathrm{Mg} \mathrm{ha}^{-1}$ ). Forests with lower levels of AGB were typically associated with non-remnant vegetation that had been cleared previously and was now in regeneration. Many of the non-remnant forests (colored in red in Fig. 7) of lower AGB were associated with brigalow (Acacia harpophylla) regrowth following clearance. By contrast, lower levels of AGB were more typical to remnant woodlands and open woodlands (e.g., those dominated by $A$. aneura within the Mulga Bioregion) occurring in the more arid areas, where growth is limited by the adverse climatic and other environmental conditions.

By only considering remnant vegetation for all structural formations combined, a single relationship between AGB and L-band $\sigma_{f}^{\mathrm{o}}$ can also be formulated, with the saturation level (for relatively wet and dry conditions) being only slightly lower than that observed for forests (For L-band $\mathrm{HV}$ and to a lesser extent HH; Fig. 9; Table IV(b)). This observation exemplifies the difficulty in developing empirical relationships with SAR data, particularly as the AGB retrieved will be different depending upon the approach used to divide the vegetation into different structural formations (e.g., forests, woodlands and open woodlands or remnant and non-remnant).

\section{DISCUSSION}

\section{A. Influence of Vegetation Structure}

Observed differences in L-band $\sigma_{f}^{\text {o }}$ between forests, woodlands and open woodlands can be attributed, in part, to the different levels of AGB supported within stands but also their overall structure. Within all three structural formations, a greater proportion of the AGB was associated with stands $<\sim 150 \mathrm{Mg} \mathrm{ha}^{-1}$. However, within this AGB range, a larger number of forests were categorised as non-remnant while most woodlands and open woodlands were categorised as remnant. At AGB levels below $\sim 150 \mathrm{Mg} \mathrm{ha}^{-1}$, differences

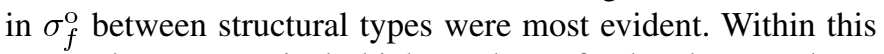
range, the comparatively higher values of L-band $\mathrm{HH}$ and $\mathrm{HV}$ $\sigma_{f}^{\mathrm{o}}$ observed for forests (mainly non-remnant) was attributed largely to greater scattering from the higher density of stems 
TABLE IV

(A) CHARACTERISTics OF THE RELATIONSHIPS BETWEen AGB $\left(\mathrm{Mg} \mathrm{ha}^{-1}\right)$ AND L-BAND $\sigma_{f}^{\circ}$ FOR Forests, WoOdLANDS AND OPEN WOODLANDS UNDER

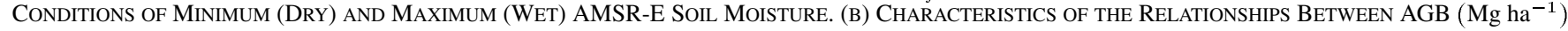
AND L-BAND $\sigma_{f}^{\circ}$ FOR FORESTS, All WOODLAND CATEGORIES AND REMNANT VEGETATION

a.

\begin{tabular}{|c|c|c|c|c|}
\hline & $\begin{array}{c}\text { AGB }\left(\mathrm{Mg} \mathrm{ha}^{-1}\right) \\
\text { at Saturation } \\
\text { Level }\end{array}$ & $\begin{array}{c}\text { Saturation level } \\
\text { (dB) }\end{array}$ & $\begin{array}{c}\text { RMSE } \\
\text { (dB) }\end{array}$ & $\begin{array}{c}\text { Dynamic Range } \\
\text { (dB) }\end{array}$ \\
\hline \multicolumn{5}{|l|}{ Forests } \\
\hline L-HV (dry) & 272 & -14.6 & 2.17 & 8.3 \\
\hline L-HV (wet) & 270 & -14.2 & 2.13 & 5.9 \\
\hline L-HH (dry) & 170 & -9.78 & 1.90 & 5.4 \\
\hline L-HH (wet) & 97 & -8.98 & 2.15 & 2.7 \\
\hline \multicolumn{5}{|l|}{ Woodlands } \\
\hline L-HV (dry) & 139 & -18.8 & 2.01 & 6.7 \\
\hline L-HV (wet) & 135 & -18.0 & 2.22 & 6.6 \\
\hline L-HH (dry) & 120 & -11.0 & 1.98 & 6.7 \\
\hline L-HH (wet) & 114 & -9.7 & 2.58 & 6.3 \\
\hline \multicolumn{5}{|c|}{ Open woodlands } \\
\hline L-HV (dry) & 65 & -20.6 & 2.15 & 8 \\
\hline L-HV (wet) & 64 & -20.0 & 2.19 & 7.89 \\
\hline L-HH (dry) & 67 & -12.6 & 2.15 & 7.37 \\
\hline L-HH (wet) & 66 & -11.5 & 2. 42 & 7.63 \\
\hline \multicolumn{5}{|l|}{ b. } \\
\hline & $\begin{array}{c}\text { AGB }\left(\mathrm{Mg} \mathrm{ha}^{-1}\right) \\
\text { at Saturation } \\
\text { Level }\end{array}$ & $\begin{array}{c}\text { Saturation level } \\
\text { (dB) }\end{array}$ & $\begin{array}{c}\text { RMSE } \\
\text { (dB) }\end{array}$ & $\begin{array}{c}\text { Dynamic Range } \\
\text { (dB) }\end{array}$ \\
\hline \multicolumn{5}{|l|}{ Remnant } \\
\hline L-HV (dry) & 247 & -14.8 & 2.29 & 11.3 \\
\hline L-HV (wet) & 232 & -14.4 & 2.34 & 11.2 \\
\hline L-HH (dry) & 136 & -10.1 & 2.05 & 8.87 \\
\hline L-HH (wet) & 111 & -9.35 & 2.36 & 9.18 \\
\hline
\end{tabular}

of a similar size class, with this being a characteristic of regenerating vegetation. The overall range of AGB was greatest for forests which resulted in the least squares regression fit trending higher compared to woodlands and particularly open woodlands, for both L-band $\mathrm{HH}$ and $\mathrm{HV} \sigma_{f}^{\mathrm{o}}$ (under dry and, to a lesser extent, wet conditions). As a consequence, the level of saturation was also comparatively greater for forests and least for open woodlands.

The greater rate of increase in $\sigma_{f}^{o}$ with AGB observed for non-remnant forests was similar to that reported for secondary forests in other regions (e.g., in the tropics). In these cases, the rapid growth of stands supporting a high density of individuals of smaller size leads to forests supporting an AGB equivalent to that of mature (remnant) open woodlands $(\sim 60-$ $120 \mathrm{Mg} \mathrm{ha}^{-1}$ ), within as short a period as 5-10 years. The rapid closure of the forest canopy and the higher density of scattering elements (branches and stems) leads to greater scattering of microwaves (e.g., [5], [74]) and hence a greater rate of increase of $\sigma_{f}^{\text {o }}$ with AGB. Within woodlands and open woodlands, comparatively lower levels of $\sigma_{f}^{\mathrm{o}}$ were observed at the same levels of AGB because of the lower densities (canopy cover between $<10$ and $30 \%)$ and heights $(<30 \mathrm{~m})$ of trees, with this collectively translating to a reduced number of scattering elements. Attenuation of microwaves is also less and greater scattering away from the sensor occurs, leading to comparatively lower values of L-band $\mathrm{HV}$ and $\mathrm{HH} \sigma_{f}^{\mathrm{o}}$.

The influence of tree density on SAR backscatter has been reported in other studies. Simulation modelling and empirical studies undertaken by [77] suggested that P-band backscatter (from coniferous stands in Canada) varied largely because of differences in stem number density, an observation supported by [78]. However, the size of scattering elements also influences the return. For example, [79] observed an L- and P-band backscatter for A. harpophylla regrowth that was similar to that of non-woody vegetation (e.g., cleared), with this attributed to stems being of insufficient size for double-bounce trunk-ground scattering to take place. In many open woodlands and woodlands, a proportion of the AGB is contained within the understorey and sub-canopy and similarly may not be of a size and density detectable by the SAR. This may further explain the relatively lower rate of increase in $\sigma_{f}^{\circ}$ with AGB observed for these structural formations compared to forests.

The research has demonstrated that the structure of vegetation influences the SAR backscatter at L-band but has resisted formulating relationships for retrieving AGB or stating the level of AGB that can be retrieved as this requires further research. Instead, the study highlights the need to develop more robust approaches to retrieval from SAR data that give consideration to vegetation structure as well as soil and vegetation moisture. The study also advocates the inclusion of other remote sensing data (e.g., Landsat FPC or LiDAR-derived height) in retrieval algorithms based on empirical relationships and also the advancement of alternative approaches to AGB retrieval.

\section{B. Influence of Rainfall and Surface Moisture}

Where ALOS PALSAR data were acquired during relatively wet periods, increases in $\sigma_{f}^{o}$ were most significant at L-band $\mathrm{HH}$ (by up to $4 \mathrm{~dB}$ ) and particularly for non-remnant forests 


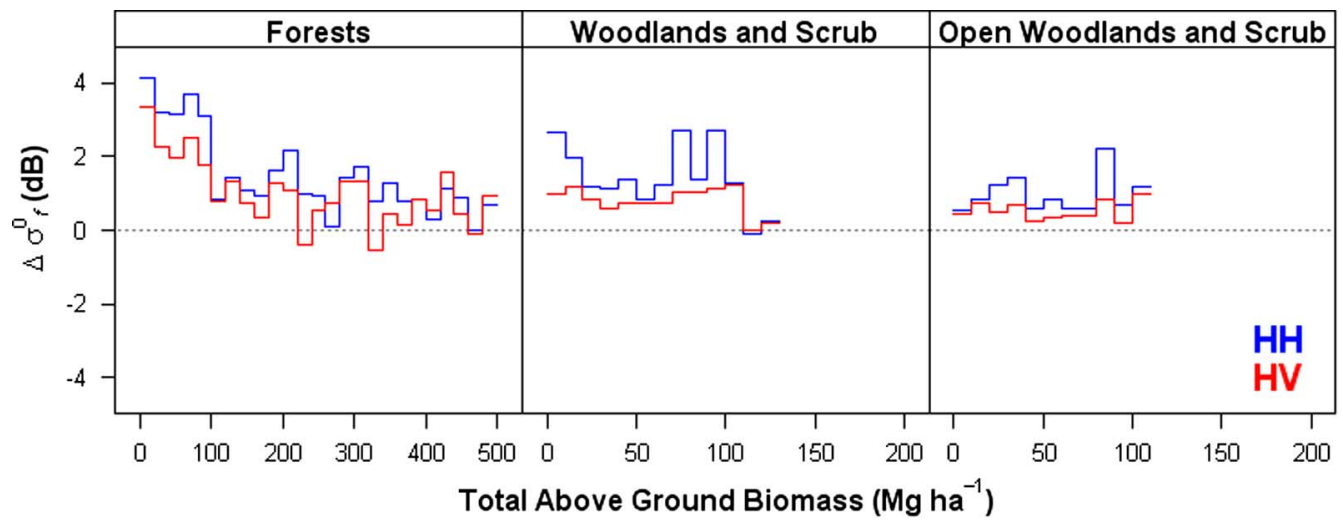

Fig. 8. Median differences in L-band $\mathrm{HH}$ and $\mathrm{HV} \sigma_{f}^{\circ}$ between the maximum and minimum observed effective vegetation water content by structural formation.

of lower AGB. The enhanced return at HH polarisation can be attributed to increased scattering from the wetter surface, primarily through double bounce interactions between the trunks and ground and direct ground returns (particularly where stem densities are relatively low). With increases in canopy cover, attenuation of microwaves is greater and hence the contribution from these scattering mechanisms is progressively reduced such that the enhancement is less prominent in forests of higher AGB. Within the woodlands and open woodlands, increases in $\sigma_{f}^{\mathrm{o}}$ were comparatively less but still greatest at L-band $\mathrm{HH}$.

Within Queensland, forests occur in the wetter regions where rainfall generally exceeds $700 \mathrm{~mm}$ per year and the moisture content of both the vegetation and soils is consistently greater compared to drier regions. Hence, $\sigma_{f}^{o}$ is maintained at a higher and more constant level. By contrast, woodlands and open woodlands typically occur in drier areas and while increases in $\sigma_{f}^{\circ}$ are observed following rainfall events, these tend to be short-lived because of high rates of evapotranspiration. Furthermore, the rainfall amounts inland are generally less compared to those towards coastal areas and hence the enhancement of backscatter may not be as great unless a large storm event occurs. Whilst the AMSR-E data reflect the increase in soil and vegetation moisture associated with rainfall events, some strips (e.g., for southeast Queensland) exhibited enhanced brightness under conditions of relatively low surface moisture conditions. Whilst this was attributed to rainfall occurring more than 5 days before the ALOS PALSAR data acquisitions, the combination of, soil moisture, effective vegetation water content and rainfall information may be more appropriate for selecting ALOS PALSAR data as they may better reflect the surface moisture conditions, particularly in areas that are densely vegetated.

\section{Retrieval of $A G B$}

Differences in the AGB level at which L-band HV and, to a lesser extent $\mathrm{HH}$, saturated were generally small between dry and wet conditions. However, the range of $\sigma_{f}^{o}$ for forests of lower AGB was reduced under wetter conditions, particularly at $\mathrm{HH}$ polarisation, and hence discrimination between levels of AGB was less. A few studies (e.g., [82]) have indicated potential for retrieval at high levels of AGB but most (e.g., [83]) have reported saturation at $\sim 60-100 \mathrm{Mg} \mathrm{ha}^{-1}$, with this varying as a function of polarisation. This low level of saturation has often been quoted as a major limitation to the retrieval of AGB from L-band SAR data. Many of these studies, however, were undertaken in tropical, temperate and boreal regions where precipitation generally exceeds evaporation, rainfall is temporally more frequent, and moisture is retained on the vegetation and within the soil for longer periods. Hence, many studies would have utilised data acquired after periods of rainfall where soil and vegetation moisture was relatively enhanced. As a consequence, L-band backscatter and scatter in the relationship would have been increased (particularly at $\mathrm{HH}$ polarisation), the dynamic range and saturation levels lowered and the ability to discriminate classes of AGB from the SAR data reduced. The retrieval of AGB and subsequent comparisons of data/results from different studies would therefore have been compromised, as would the formulation of a regional or global algorithm. For this reason, moisture on the surface of the vegetation and ground and within the soil should be considered when retrieving AGB from SAR data, regardless of frequency. Similarly, studies focusing on the retrieval of moisture itself from satellite sensor data need to take account of the influence of vegetation and soil characteristics. The two are, however, intricately linked and so retrieval of one needs to consider the other. For this reason, algorithms that couple both vegetation structure and surface moisture conditions should be advanced in parallel.

Relative differences in L-band backscatter at similar levels of AGB and between forests, woodlands and open woodlands became apparent because field-based estimates of AGB from a wide range of structural types were integrated with ALOS PALSAR data acquired and consistently processed across a large region. Through this approach, the common limitation of focusing on single biomes or structural forms and comparing results undertaken independently at different locations and times and often using different sensors were largely overcome. The capacity to identify and develop relationships for the different structural types has allowed some of the scatter observed in previous studies to be explained and, as a result, conveyed greater potential for retrieving AGB from L-band SAR intensity data. Establishing an algorithm to retrieve the AGB that considers different structural types is nevertheless complicated, particularly where gradients (e.g., between woodlands and open woodlands) occur, and most likely needs to consider continuous variables such as FPC, rainfall or soil nutrients. Furthermore, 


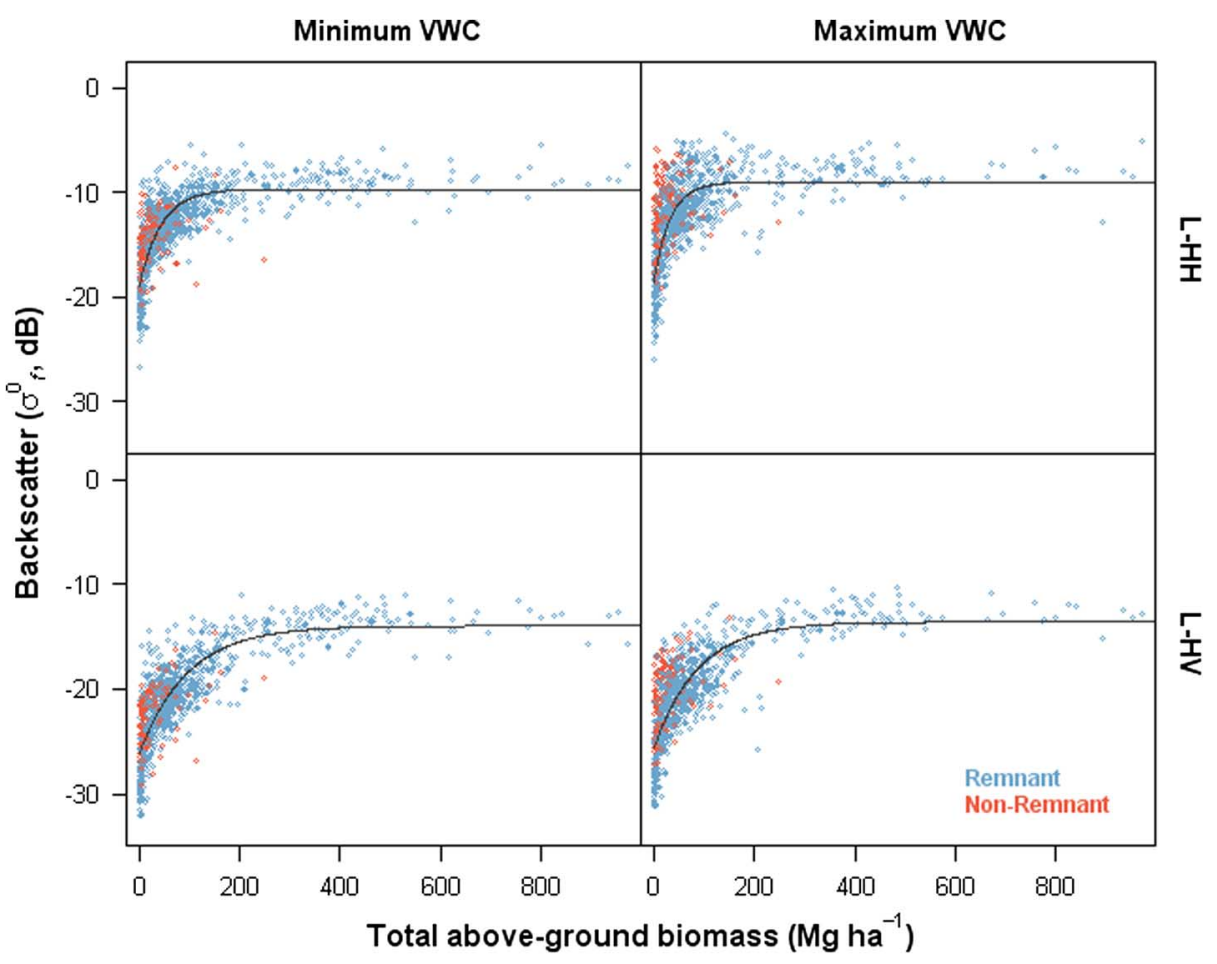

Fig. 9. Least squares fits between L-band HH and HV $\sigma_{f}^{\circ}$ and AGB based on remnant forest only and ALOS PALSAR data acquired during periods of relative minimum and maximum effective vegetation water content (VWC). Points associated with non-remnant forest are also indicated but were not used in the fitting.

in regions outside of Queensland (including within Australia) supportive mapping (e.g., equivalent to the RE data) may not be available to inform decisions relating to a priori classification of the landscape and appropriate application of retrieval algorithms.

More detailed analysis is required to incorporate the errors associated with field measurements of AGB. The field data employed for this study were collected at a range of resolutions, and the hiatus between field measurements and remote-data capture was sufficient in some cases to include natural disturbances. The structure of the vegetation will also require finer discrimination (e.g., by dominant species) than the coarse stratification employed here. To standardize across studies, all stems less than $5 \mathrm{~cm}$ dbh were deleted from the AGB estimates. This size class (i.e., $<5 \mathrm{~cm} \mathrm{dbh)} \mathrm{can} \mathrm{represent} \mathrm{a} \mathrm{large} \mathrm{proportion} \mathrm{of} \mathrm{AGB} \mathrm{for}$ some vegetation types and structures (e.g., regrowth), and the density of small trees may have a distinctive influence on the radar return signal. Canopy health may also be influential and could be modeled using surrogates such as rainfall deficit [40], fire scar distributions [84] and FPC mapping [85]. The estimates of AGB generated included both live and dead trees. A number of studies (e.g., [86]) have indicated sensitivity of L-band SAR to dead standing timber and so the inclusion of these trees considers their contribution to the overall backscatter at L-band. Measurement of dead trees when standing is therefore considered essential when formulating relationships between L-band SAR data and AGB. Whilst rainfall and canopy closure are factors that impact on the capacity to retrieve AGB, other factors include the surface roughness, the underlying geology and the presence of surface water below the canopy. The areas affected can often be identified through reference to the imagery themselves or ancillary layers (e.g., geology maps).

\section{Implications for Mapping AGB From ALOS PALSAR Mosaics and Detecting Change}

For retrieving AGB across Queensland based on empirical regression-based techniques, mosaics generated from ALOS PALSAR data acquired during relatively dry periods are essential. For Queensland, up to three images were acquired in any one year. However, the capacity to acquire ALOS PALSAR of sufficient temporal frequency, such that data are acquired during dry periods, will vary regionally and be dictated by the ALOS observation strategy. To ensure the provision of sufficient data for generating mosaics for AGB estimation, a more frequent repeat period or the use of data from other years is desirable. However, techniques such as scattering-based inversion [e.g., [87]] may provide an alternative for retrieval as these consider the moisture content of vegetation and the soil.

The use of AMSR-E data to inform on the optimal combination of ALOS PALSAR data when ordering or compositing is advantageous as these are available globally and on a daily basis. At the higher frequencies used by AMSR-E data, soil moisture retrieval is more successful over non-vegetated or sparsely vegetated areas but may be compromised over vegetated areas. Conversely, the retrieval of effective vegetation moisture content may be better in forests with a greater degree of canopy closure. For this reason, both the AMSR-E soil moisture and effective vegetation water content data should be used to provide a relative indication of high or low moisture conditions to guide 
the selection of ALOS PALSAR data (e.g., for biophysical retrieval, classification), Whilst the selection and use of ALOS PALSAR data for local areas can be undertaken with reference to AMSR-E estimates of surface moisture for individual $(25 \mathrm{~km})$ pixels, these values should be treated with some caution because of, for example, uncertainty associated with sensor calibration and the presence of vegetation. Where available, rainfall surfaces for the days leading up to data acquisition would also be useful as they provide an indication of moisture potentially retained on the surface of vegetation and the soil. However, for many regions, the frequency of ALOS PALSAR data acquisition rates may be insufficient to obtain dry images, particularly where rainfall is frequent through the year. A solution would be to provide greater repeat coverage of ALOS PALSAR or other L-band SAR data and should be considered in the design of sensors and future observation strategies.

Predictive models for retrieving AGB from ALOS PALSAR data have not been provided, although these will be the topic of a forthcoming paper. Despite a close correspondence between the L-band HV and AGB, considerable scatter still occurs and the potential for retrieval is reduced at higher levels of AGB. In addition to structural variability, this can be attributable to factors including errors associated with geolocation of plot and image data, measurement error and bias in field measurements and the allometric equations for estimating the AGB of tree species contained, relative differences in minimum moisture conditions for different regions, and SAR speckle noise. For this reason, research is focusing on developing a robust approach to AGB retrieval, either using ALOS PALSAR data alone or in combination with other remote sensing datasets (e.g., Landsat-derived FPC time-series, climate variables).

\section{SUMMARY AND CONCLUSIONS}

By utilising ALOS PALSAR and field data acquired across a range of structural vegetation types in Queensland, Australia, this study has obtained a unique insight into the relationships between SAR backscatter and AGB. The research has established the following.

- Relatively seamless mosaics of ALOS PALSAR L-band $\mathrm{HH}$ and HV data can be generated when using strip data acquired during periods when surface moisture is relatively low. Such an approach has led to a mosaic of ALOS PALSAR data being successfully generated for Queensland for 2007 without the need for complex correction algorithms.

- Differences in the relationship between AGB and L-band $\sigma_{f}^{\text {o }}$ were observed between forests, woodlands and open woodlands, with these attributed to differences in structure, namely density and size class distributions. Lower returns from woodlands and open woodlands was also attributable to lower interaction of L-band microwaves with smaller stems and branches and, by virtue of the open canopy, increased ground scattering away from the sensor.

- Levels of saturation were comparatively greatest for forests and least for open woodlands and differed largely because of differences in the naturally occurring levels of AGB between structural formations and overall structure as a function of growth stage.
- During wetter conditions, the saturation level remained similar for forests at L-band HV but was reduced at L-band $\mathrm{HH}$. However, at both $\mathrm{HH}$ and $\mathrm{HV}$ polarisations and for all structural formations, the dynamic range was reduced, with this then limiting ability to discriminate different levels of AGB. Greater sensitivity of L-band HH to surface moisture conditions was also evident, with this attributed primarily to enhanced double-bounce scattering from trunk-ground interactions.

- Spatial information on moisture conditions is necessary to guide the selection of ALOS PALSAR data in the development and application of algorithms for biophysical retrieval (e.g., AGB) or classifying landscapes. In situ measurements of soil and vegetation moisture should ideally be taken at the time of the satellite overpass to support such retrieval. However, given the practical limitations of obtaining such measurements over large areas, the use of AMSR-E or interpolated rainfall data is recommended. These data are widely available and should be consulted when selecting scenes for many applications, regardless of whether these are directed towards local areas or large regions.

Final conclusions regarding the potential and limitations of ALOS PALSAR for estimating AGB at a regional level require more detailed analysis, but this study indicates some potential for calibrating these data using field measurements and incorporating information on the structural attributes of vegetation. Whilst limitations in the use of ALOS PALSAR for estimating AGB at a regional level still remain, this research has shed new light onto why retrieval from L-band SAR data using regression-based techniques has been compromised in the past. New avenues for utilizing these data have been highlighted with potential benefits at a global level.

\section{ACKNOWLEDGMENT}

This work has been undertaken within the framework of the JAXA Kyoto \& Carbon Initiative. ALOS PALSAR data were provided by JAXA EORC. Masanob Shimada (JAXA) and Daisuke Sang (RESTEC) are particularly thanked for their provision of multi-temporal datasets. Luigi John Renzullo and Catherine Ticehurst (CSIRO) are thanked for providing the AMSR-E data. The authors would also like to thank the three anonymous reviewers and also Scott Hensley (NASA JPL) for their comments, which have contributed to further understanding of AGB and SAR data relationships. The UK Natural Environment Research Council (NERC) are also thanked for support.

\section{REFERENCES}

[1] D. J. Baker, G. Richards, A. Grainger, P. Gonzalez, S. Brown, R. DeFries, A. Held, J. Kellndorfer, P. Ndunda, D. Ojima, P. Skrovseth, C. Souza, and F. Stolle, "Achieving forest carbon information with higher certainty: A five-part plan," Environmental Science and Policy, vol. 13, pp. 249-260.

[2] R. A. Houghton, "Aboveground forest biomass and the global carbon balance," Global Change Biology, vol. 11, pp. 945-958, 2005.

[3] C. Dobson, F. Ulaby, L. Pierce, T. Sharik, K. Bergen, J. Kellndorfer, J. R. Kendra, E. Li, Y. C. Lin, A. Nashashibi, K. Sarabandi, and P. Siqueira, "Estimation of forest biomass characteristics in northern Michigan with SIR-C/X-SAR data," IEEE Trans. Geosci. Remote Sens., vol. 33, no. 4, pp. 877-894, 1995. 
[4] M. L. Imhoff, "Radar backscatter and biomass saturation: Ramifications for global biomass inventory," IEEE Trans. Geosci. Remote Sens., vol. 33, no. 2, pp. 511-518, 1995

[5] D. H. Hoekman, M. J. Quiñones, and M. J. , "Land cover type and biomass classification using AirSAR data for evaluation of monitoring scenarios in the colombian amazon," IEEE Trans. Geosci. Remote Sens., vol. 38, no. 2, pp. 685-696, 2000.

[6] J. E. S. Fransson and H. Israelsson, "Estimation of stem volume in boreal forests using ERS-1 C-band and JERS-1 L-band SAR data," Int. J. Remote Sens., vol. 20, pp. 123-137, 1999.

[7] S. Saatchi, K. Halligan, D. G. Despin, and R. Crabtree, "Estimation of forest fuel load from radar remote sensing," IEEE Trans. Geosci. Remote Sens., vol. 45, no. 6, pp. 1726-1740, 2007.

[8] R. M. Lucas, N. Cronin, N. A. Lee, M. Moghaddam, C. Witte, and P. Tickle, "Empirical relationships between AIRSAR backscatter and LiDAR-derived forest biomass, Queensland, Australia," Remote Sens. Environ., vol. 100, pp. 407-425, 2006.

[9] M. Santoro, L. Eriksson, L. J. Askne, and C. Schmullius, "Assessment of stand-wise stem volume retrieval in boreal forest from JERS-1 L-band SAR backscatter," Int. J. Remote Sens., vol. 27, no. 16, pp. 3425-3454, 2006

[10] M. C. Dobson, F. T. Ulaby, T. Le Toan, A. Beaudoin, E. S. Kasischke, and N. Christensen, "Dependence of radar backscatter on coniferous forest biomass," IEEE Trans. Geosci. Remote Sens., vol. 30, no. 2, pp. 412-415, 1992.

[11] T. Le Toan, A. Beaudoin, J. Riom, and D. Guyon, "Relating forest biomass to SAR data," IEEE Trans. Geosci. Remote Sens., vol. 30, no. 2, pp. 403-411, 1992.

[12] J. Pulliainen, M. Engdahl, and M. Hallikainen, "Feasibility of multitemporal interferometric SAR data for stand-level estimation of boreal forest stem volume," Remote Sens. Environ., vol. 85, no. 4, pp. 397-409, 2003.

[13] H. Balzter, C. S. Rowland, and P. Saich, "Forest canopy height and carbon estimation at Monks Wood National Nature Reserve, UK, using dual-wavelength SAR interferometry," Remote Sens. Environ., vol. 108 , no. 3 , pp. 224-239, 2007.

[14] P. Hyde, R. Nelson, D. Kimes, D. , and E. Levine, "Exploring LiDARRaDAR synergy_-Predicting above ground biomass in a southwestern ponderosa pine forest using LiDAR, SAR and InSAR," Remote Sens. Environ., vol. 106, no. 1, pp. 28-38, 2007.

[15] J. A. Armston, J. M. B. Carreiras, R. M. Lucas, and M. Shimada, "ALOS PALSAR backscatter mosaics for Queensland, Australia: The impact of surface moisture and incidence angle," in Proc. 15th Australian Remote Sensing and Photogrammetry Conf., Alice Springs, Australia, Sep. 2010.

[16] V. J. Neldner, B. A. Wilson, E. J. Thompson, and H. A. Dillewaard, "Methodology for Survey and Mapping of Regional Ecosystems and Vegetation Communities in Queensland", ver. 3.1 Queensland Herbarium Environmental Protection Agency, Brisbane, Australia, 2005.

[17] P. Sattler and R. Williams, "The Conservation Status of Queensland's Bioregional Ecosystems", Environmental Protection Agency, Queensland Government, Brisbane, Australia, 1999.

[18] R. L. Specht, The Australian Environment. Melbourne, Australia: CSIRO Australia and Melbourne Univ. Press, 1970.

[19] J. Walker and M. S. Hopkins, "Vegetation," in 1990 Australian Soil and Land Survey Field Handbook, R. C. McDonald, R. F. Isbell, J. G. Speight, J. Walker, and M. S. Hopkins, Eds., 2nd ed. Canberra, Australia: CSIRO Australia, 1990.

[20] A. Accad, V. J. Neldner, B. A. Wilson, and R. E. Niehus, "Remnant Vegetation in Queensland. Analysis of Remnant Vegetation 1997-1999-2000-2003-2005, Including Regional Ecosystem Information", Queensland Herbarium, Qld. Environmental Protection Agency, Brisbane, Australia, 2008.

[21] J. S. Olson, J. A. Watts, and L. J. Allison, "Major World Ecosystem Complexes Ranked by Carbon in Live Vegetation: A Database", U.S. Dept. Energy, Oak Ridge, Tennessee, Report NDP-017, 1985.

[22] R. M. Gifford, N. P. Cheney, J. C. Noble, J. S. Russell, A. B. Wellington, and C. Zammit, "Australian land use, primary production of vegetation and carbon pools in relation to atmospheric carbon dioxide concentration," in Australia's Renewable Resources Sustainability and GlobalChange. International Geosphere Biosphere Programme Australia, Planning Workshop. Bureau of Rural Resources Proceedings No. 14. AGPS Canberra, R. M. Gifford and M. M. Barson, Eds., 1992, pp. 151-187.
[23] B. K. Henry, T. Danaher, G. M. McKeon, and W. H. Burrows, "A review of the potential role of greenhouse gas abatement in vegetation management in Queensland's rangelands," Rangeland J., vol. 24, pp. 112-132, 2002

[24] S. L. Berry and M. L. Roderick, "Changing Australian vegetation from 1788 to 1988: Effects of $\mathrm{CO}_{2}$ and land use change," Australia. J. Bot., vol. 54, pp. 325-328, 2006.

[25] H. Keith, D. J. Barrett, and R. Keenan, "Review of Allometric Relationships for Estimating Woody Biomass for New South Wales, the Australian Capital Territory, Victoria, Tasmania and South Australia", Australian Greenhouse Office, Canberra, National Carbon Accounting System Technical Report No. 5B, 2002.

[26] W. H. Burrows, B. K. Henry, P. V. Back, M. B. Hoffmann, L. J. Tait, E. R. Anderson, N. Menke, T. Danaher, J. O. Carter, and G. M. McKeon, "Growth and carbon stock change in eucalypt woodlands in northeast Australia: Ecological and greenhouse sink implications," Global Change Biol., vol. 8, no. 8, p. 769, 2002.

[27] P. K. Tickle, A. Lee, R. M. Lucas, J. Austin, and C. Witte, "Quantifying Australian forest and woodland structure and biomass using large scale photography and small footprint Lidar," Forest Ecol. Manage., vol. 223, pp. 379-394, 2006

[28] A. Zerihun, K. D. Montagu, M. B. Hoffmann, and S. G. Bray, "Patterns of below- and aboveground biomass in EUCALYPTUS POPULNEA woodland communities of Northeast Australia along a rainfall gradient," Ecosystems, vol. 9, no. 4, pp. 501-513, 2006.

[29] A. Rosenquist, M. Shimada, N. Ito, and M. Watanabe, "ALOS PALSAR: A pathfinder mission for global-scale monitoring of the environment," IEEE Trans. Geosci. Remote Sens., vol. 45, no. 11, pp. 3307-3316, 2007.

[30] U. Wegmüller, C. Werner, and T. Strozzi, "SAR interferometric and differential interferometric processing," in Proc. IGARSS'98, Seattle, Washington, Jul. 6-10, 1998, pp. 1106-1108.

[31] U. Wegmüller, "Automated terrain corrected SAR geocoding," in Proc. IGARSS'99, Hamburg, Germany, Jun. 28-Jul. 2 1999, pp. 1712-1714.

[32] M. Shimada, O. Isoguchi, T. Tadono, and K. Isono, "PALSAR radiometric and geometric calibration," IEEE Trans. Geosci. Remote Sens., vol. 47, no. 12, Dec. 2009.

[33] M. Santoro, J. E. S. Fransson, L. E. B. Eriksson, M. Magnusson, L. M. H. Urlander, and H. Olsson, "Signatures of ALOS PALSAR L-band backscatter in Swedish Forest," IEEE Trans. Geosci. Remote Sens., vol. 47, no. 12, pp. 4001-4019, 2009.

[34] C. J. Thiel, C. Thiel, and C. C. Schmullius, "Operational large-area forest monitoring in Siberia using ALOS PALSAR summer intensities and winter coherence," IEEE Trans. Geosci. Remote Sens., vol. 47, no. 12, pp. 3993-4000, 2009.

[35] S. Jeffrey, J. O. Carter, K. B. Moodie, and A. R. Beswick, "Using spatial interpolation to construct a comprehensive archive of Australian climate data," Environm. Model. Software, vol. 16, p. 309-3, 2001

[36] E. G. Njoku, T. J. Jackson, V. Lakshmi, T. K. Chan, and S. V. Nghiem, "Soil moisture retrieval from AMSR-E," IEEE Trans. Geosci. Remote Sens., vol. 41, no. 2, pp. 215-229, 2003.

[37] E. G. Njoku, AMSR-E/Aqua L2B Surface Soil Moisture, Ancillary Parms, \& QC EASE-Grids V002, 2007 AMSR-E Data. National Snow and Ice Data Center, Boulder, Colorado, USA, 2004, Digital media, updated daily.

[38] L. J. Renzullo, D. J. Barrett, A. S. Marks, M. J. Hill, J. P. Guerschman, Q. Mu, and S. Running, "Multi-sensor model-data fusion for estimation of hydrologic and energy flux parameters," Remote Sens. Environ., vol. 112, pp. 1306-1319, 2008.

[39] M. Laidlaw, Griffith University, (unpublished data).

[40] D. Metcalfe, CSIRO Atherton, (unpublished data).

[41] R. J. Fensham and J. E. Holman, "Temporal and spatial patterns in drought-related tree dieback in Australian savanna," J. Appl. Ecol., vol. 36, pp. 1035-1050, 1999.

[42] R. J. Fensham, R. J. Fairfax, and D. P. Ward, "Drought-induced tree death in savanna," Global Change Biol., vol. 15, pp. 380-387, 2009.

[43] R. J. Fensham and R. J. Fairfax, "Drought-related tree death of savanna eucalypts: Species susceptibility, soil conditions and root architecture," J. Vegetation Sci., vol. 18, pp. 71-80.

[44] R. J. Fensham, R. J. Fairfax, and R. J. , "Preliminary assessment of gidgee (Acacia Cambagei) woodland thickening in the Longreach district, Queensland," Rangeland J., vol. 27, pp. 159-168, 2005.

[45] R. J. Fensham, Queensland Dept. Environment and Natural Resources, unpublished data, 2007.

[46] J. Dwyer, unpublished data Univ. Queensland, Brisbane, Australia, 2008. 
[47] M. E. Bowen, C. A. McAlpine, A. P. N. House, and G. C. Smith, "Agricultural landscape modification increases the abundance of an important food resource: Mistletoes, birds and brigalow," Environm. Conserv., vol. 142, pp. 122-133, 2009.

[48] R. J. Fairfax, unpublished data Queensland Dept. Environment and Natural Resources, Brisbane, Australia, 2009.

[49] T. Eyre, unpublished data Queensland Dept. Environment and Natural Resources, Brisbane, Australia, 2009.

[50] D. W. Butler, "Seed dispersal syndromes and the distribution of woody plants in south-east Queensland's vine-forests," Ph.D. dissertation, Univ. Queensland, Brisbane, Australia, 2004.

[51] D. W. Butler, R. J. Fairfax, and R. J. Fensham, "Impacts of tree invasion on floristic composition of subtropical grasslands on the Bunya Mountains, Australia," Australia. J. Bot., vol. 54, no. 3, pp. 261-270, 2006.

[52] R. J. Fensham, "Biomass of Brisbane City Council Bushlands", 2009, Report to Brisbane City Council, Australia, 30 pp.

[53] M. Laidlaw, M. Olsen, R. L. Kitching, and M. Greenway, "Tree floristic and structural characteristics of one hectare of subtropical rainforest in Lamington National Park, Queensland," in Proc. Roy. Soc. Qld., 2000, vol. 109, pp. 91-105.

[54] M. J. Laidlaw, W. J. F. McDonald, R. J. Hunter, and R. L. Kitching, "Subtropical rainforest turnover along an altitudinal gradient," Memoirs of the Queensland Museum, (in press).

[55] M. Laidlaw, "Variations in rainforest vegetation along a latitudinal gradient," Honours thesis, Griffith Univ., Brisbane, Australia, 1999.

[56] R. J. Fensham and R. J. Fairfax, "Effect of photoscale, interpreter bias and land type on woody crown-cover estimates from aerial photography," Australia. J. Bot., vol. 55, pp. 457-463, 2007.

[57] R. J. Fensham, R. J. Fairfax, D. W. Butler, and D. M. J. S. Bowman, "Effect of fire and drought in a tropical eucalypt savanna colonized by rain forest," J. Biogeogr., vol. 30, pp. 1405-1414, 2003.

[58] S. G. Bray, E. S. Krull, B. P. Harms, N. Baxter, M. Rutherford, M. Yee, and L. Cogle, "Assessment of Vegetation Change in the Burdekin Catchment of Queensland-Project Report Q106091,” Dept. Primary Industries and Fisheries, Queensland, Australia, 2006.

[59] DNRW, "Land Cover Change in Queensland 2006-07: A Statewide Landcover and Trees Study (SLATS) Report," Queensland Government, Brisbane, Australia, Dec. 2008 [Online]. Available: http://www.nrw.qld.gov.au/slats/pdf/land_cover_change0607/landcover_change_report0607.pdf, 2008

[60] J. C. Scanlan, "Woody overstorey and herbaceous understorey biomass in Acacia harpophylla (brigalow) woodlands," Australia. J. Ecol., vol. 16, pp. 521-529, 1991.

[61] G. Harrington, "Estimation of above-ground biomass of trees and shrubs in a Eucalyptus populnea F. Muell. Woodland by regression of mass on trunk diameter and plant height," Australia. J. Bot., vol. 27, pp. 135-143, 1979.

[62] R. J. Fensham, R. J. Fairfax, J. E. Holman, and P. J. Whitehead, "Quantitative assessment of vegetation structural attributes from aerial photography," Int. J. Remote Sens., vol. 23, pp. 2293-2317, 2002.

[63] W. E. Westman and R. W. Rogers, "Biomass and structure of a subtropical eucalypt forest, North Stradbroke Island," Australia. J. Bot., vol. 25, pp. 171-191, 1977.

[64] R. J. Williams, A. Zerihun, K. D. Montagu, M. Hoffman, L. B. Hutley, and X. Chen, "Allometry for estimating aboveground tree biomass in tropical and subtropical eucalypt woodlands: Towards general predictive equations," Australia. J. Bot., vol. 53, pp. 607-719, 2005.

[65] D. Eamus, K. McGuinness, and W. Burrows, "Review of Allometric Relationships for Estimating Woody Biomass for Queensland, the Northern Territory and Western Australia," Australian Greenhouse Office, National Carbon Accounting System Technical Report No. $5 \mathrm{~A}, 2000$.

[66] J. L. Frangi and A. E. Lugo, "Ecosystem dynamics of a subtropical floodplain forest," Ecological Monographs, vol. 55, pp. 351-369, 1985.

[67] A. P. O'Grady, X. Chen, D. Eamus, and L. B. Hutley, "Composition, leaf area index and standing biomass of eucalypt forests near Darwin in the Northern Territory, Australia," Australia. J. Bot., vol. 48, pp. 629-638, 2000.

[68] W. H. Burrows, M. B. Hoffman, J. F. Compton, P. V. Back, and L. Tait, "Allometric relationships and community biomass estimates for some dominant eucalypts in Central Queensland woodlands," Australia. J. Bot., vol. 48, pp. 707-714, 2000.

[69] J. Ilic, D. Boland, M. McDonald, G. Downes, and P. Blakemore, "Wood Density Phase 1-State of Knowledge," Australian Greenhouse Office, National Carbon Accounting System Technical Report No. 18, 2000.
[70] F. A. Ximnenes, W. D. Gardner, and J. F. Marchant, "Total Biomass Measurement and Recovery of Biomass in Log Products in Spotted Gum (Corymbia Maculata) Forests of SE NSW," Australian Greenhouse Office, Canberra, National Carbon Accounting System Technical Report No. 47, 2004.

[71] H. T. L. Stewart, D. W. Flinn, and B. C. Aeberli, "Above-ground biomass of a mixed eucalypt forest in eastern Victoria," Australia. J. Bot., vol. 27, pp. 725-740, 1979.

[72] G. B. Applegate, "Biomass of Blackbutt (Eucalyptus Pilularisi) Forests on Fraser Island," Univ. New England. Armidale, New South Wales, Australia, 1982.

[73] C. A. Rueda, J. A. Greenberg, and S. L. Ustin, "StarSpan: A Tool for Fast Selective Pixel Extraction From Remotely Sensed Data," Center for Spatial Technologies and Remote Sensing (CSTARS), Univ. California at Davis. Davis, CA, USA, 2005.

[74] A. Luckman, J. Baker, M. Honzak, and R. Lucas, "Tropical forest biomass density estimation using JERS-1 SAR: Seasonal variation, confidence limits, and application to image mosaics," Remote Sens. Environ., vol. 63, pp. 126-139, 1998.

[75] A. W. Moore, J. S. Russell, and J. E. Coaldrake, "Dry matter and nutrient content of a subtropical semiarid forest of Acacia harpophylla F Muell (brigalow)," Australia. J. Bot., vol. 15, pp. 11-24, 1967.

[76] M. Shimada, O. Isoguchi, T. Tadono, R. Higuchi, and K. Isono, PALSAR CALVAL Summary (AXA-P1193), Earth Observation Research and application Center (EORC) Japan Aerospace and Exploration Agency (JAXA), 2009.

[77] G. Smith-Jonforsen, B. Folkesson, and B. Hallberg, "Effects of forest biomass and stand consolidation on P-band backscatter," IEEE Geosci. Remote Sens. Lett., vol. 4, no. 4, pp. 669-673, 2007.

[78] I. H. Woodhouse, "Predicting backscatter-biomass and height-biomass trends using a macroecology model," IEEE Trans. Geosci. Remote Sens., vol. 44, pp. 871-877, 2006.

[79] R. M. Lucas, N. Cronin, M. Moghaddam, A. Lee, J. A. Armston, P. Bunting, and C. Witte, "Integration of radar and Landsat-derived foliage projected cover for woody regrowth mappingm, Queensland, Australia," Remote Sens. Environ., vol. 100, pp. 388-406, 2006.

[80] A. Held, C. Ticehurst, L. Lymburner, and M. Williams, "High resolution mapping of tropical mangrove ecosystems using hyperspectral and radar remote sensing," Int. J. Remote Sens., vol. 24, pp. 2739-2759, 2003.

[81] R. M. Lucas, A. L. Mitchell, A. Rosenqvist, C. Proisy, A. Melius, and C. Ticehurst, "The potential of L-band SAR for quantifying mangrove chacteristics and change: Case studies from the tropics," Aquatic Cons. Marine Freshwater Ecosyst., vol. 17, pp. 245-264, 2007.

[82] J. M. Austin, B. G. Mackey, and K. P. Van Niel, "Estimating forest biomass using satellite radar: An exploratory study in a temperate Australian Eucalyptus forest," Forest Ecol. Manage., vol. 176, pp. 575-583, 2002.

[83] A. Luckman, J. Baker, T. M. Kuplich, C. C. F. Yanasse, and A. C. Frery, "A study of the relationship between radar backscatter and regenerating tropical forest biomass for spaceborne SAR instruments," Remote Sens. Environ., vol. 60, pp. 1-13, 1997.

[84] R. Russell-Smith, R. Williams, P. Whitehead, and M. J. Flannigan, "Fire and savanna landscapes in northern Australia: Regional lessons and global challenges," Special Issue: Int. J. Wildland Fire, vol. 12, no. 3 and 4, 2003.

[85] J. A. Armston, R. J. Denham, T. Danaher, P. F. Scarth, and T. N. Moffiet, "Prediction and validation of foliage projective cover from Landsat-5 TM and Landsat-7 ETM+ imagery," J. Appl. Remote Sens., vol. 3, p. 033540, 2009.

[86] R. M. Lucas, A. Accad, L. Randall, P. Bunting, and J. Armston, "Assessing human impacts on Australian forests through integration of airborne/spaceborne remote sensing data," in Patterns and Processes in Forest Landscapes: Multiple Uses and Sustainable Management, R. Lafortezza, J. Chen, G. Sanesi, and T. R. Crow, Eds. New York: Springer, 2008, pp. 213-240.

[87] M. Moghaddam and S. Saatchi, "Monitoring tree moisture using an estimation algorithm applied to SAR data from Boreas.," IEEE Trans. Geosci. Remote Sens., vol. 37, pp. 901-916, Mar. 1999.

[88] Y. Tang, "Maintenance and dynamics of rainforest edges," Ph.D. dissertation, Griffith Univ., Brisbane, Australia, 2008.

[89] M. J. Laidlaw, "Spatial and temporal dynamics of Australian Rainforests," Ph.D. dissertation, Univ. of Queensland, Brisbane, Australia, 2010. 
Richard Lucas received the B.Sc. (Jt. Hons) in biology and geography and the Ph.D. in 1986 and 1989, respectively, both from the University of Bristol, U.K. He worked subsequently at the University of Wales, Swansea, U.K. (1991-1996), the Bureau of Rural Sciences, Canberra, Australia (1996-1998), and the University of New South Wales, Sydney, Australia (1998-2000). Since 2001, he has worked at Aberystwyth University, Wales, U.K. His research focuses on the integration of airborne and spaceborne optical, radar and lidar data for understanding and quantifying change in terrestrial ecosystems.

John Armston received the B.Sc. degree in geography (Hons) from the University of Queensland, Brisbane, Australia, in 2004. He has worked as a remote sensing research scientist for the Queensland Department of Environment and Resource Management (QDERM) and is currently studying for a Ph.D. at the University of Queensland.

His interests are in detecting change in canopy structure using waveform LiDAR and integration of polarimetric radar and Landsat-time-series for large area mapping and monitoring of woody vegetation in eastern Australia.

Russell Fairfax received the B.App.Sc. degree in natural systems and wildlife management from the University of Queensland, Australia, in 1993.

He has worked at the Queensland Herbarium since 1994. His main interests are in ecology and conservation.

Rod Fensham was awarded the 2005 Sherman Eureka Prize for his research that contributed to regulations that phase out broadscale land clearing in Queensland. His research relates to the ecology and conservation of native vegetation. He tries to disseminate his findings not only by publishing but also through conservation planning, policy and practice.

Arnon Accad received the B.Sc. degree in computer science and the Ph.D. in vegetation modelling from the University of Queensland, Australia, in 1987 and 2003, respectively.

From 1988 to 1991, he was involved in the coordination of the Queensland Government Geographic Information Systems (GIS) and has subsequently worked with the Wet Tropics Management Authority. He currently works at the Queensland Herbarium (now part of the Queensland Department of Environment and Resource Management) and is an Adjunct Associate Professor with the University of the Sunshine Coast.

Joao Carreiras received the B.Sc. and Ph.D. degrees in forestry from the Technical University of Lisbon, Portugal, in 1993 and 2005, respectively.

$\mathrm{He}$ continued as a Research Associate focusing on machine learning algorithms for mapping land cover classes in the Brazilian Legal Amazon and fire mapping in Portugal. Since July 2007, he has worked at the Tropical Research Institute (IICT), Lisbon, focusing on the use of ALOS PALSAR data for forest biomass retrieval.

Jack Kelley received the Assoc. Diploma in cartography from the Queensland Institute of Technology, Australia, in 1988 and the B.App.Sc. in computing from the Queensland University of Technology, Australia, in 1992.

Since 1992, he has worked in the Queensland Herbarium supporting Queensland's vegetation mapping program.

Peter Bunting received the B.Sc. degree in computing science and the Ph.D. in remote sensing (geography) from Aberystwyth University in 2004 and 2007, respectively.

He was appointed as a Lecturer at Aberystwyth University, Wales, U.K., in 2007. His research focuses on the development of algorithms for retrieving biophysical properties of forests and classifying landscapes.
Dan Clewley received the B.Sc. degree in physics and the M.Sc. degree in remote sensing and GIS, both from Aberystwyth University, Wales, U.K. He is currently undertaking a NERC-funded Ph.D. in radar modeling in relation to wooded savannas in conjunction with the University of Michigan, Ann Arbor, MI, USA.

Steven Bray received the B.Agr.Sc. in 1993 and Ph.D. in 2004, both from the University of Queensland, Australia.

As a Senior Scientist in sustainable grazing systems with the Queensland Government, his research has included monitoring and understanding the woody plant dynamics in Queensland's grazed woodlands and understanding the greenhouse gas budget of the beef industry and the impact of grazing land condition and management on soil carbon stocks.

Dan Metcalfe received the B.Sc. degree in botany from the University of Bristol, U.K. in 1991 and the Ph.D. from the University of Cambridge, U.K. in 1994.

From 1994 to 1997, he worked as a NERC-funded postdoctoral research scientist at the CSIRO Tropical Forest Research Centre (TRFC) in Atherton, Queensland. From 1998 to 2008 he was a lecturer at the University of Brighton before returning to CSIRO Atherton in 2004.

John Dwyer received the M.Sc. and Ph.D. degrees in botany and plant ecology from the University of Queensland, Australia, in 2009. His Ph.D. focused on the ecology, restoration and carbon potential of brigalow regrowth in Queensland, Australia.

$\mathrm{He}$ is currently a Research Scientist at the University of Western Australia exploring novel annual plant assemblages in York Gum woodlands.

Michiala Bowen received the Ph.D. degree from the University of Queensland, Brisbane, Australia, in 2009, where she is currently a Research Fellow.

Her current research is focusing on understanding the spatial and temporal patterns in secondary forest regeneration that influence wildlife populations in highly modified agricultural landscapes.

Teresa Eyre received the B.Sc. degree in ecology and climatology from Macquarie University in 1988 and the Ph.D. in terrestrial ecology from Southern Cross University in 2002.

She has been a principal research ecologist with the Queensland Department of Environment and Resource Management since 1988. During this time, she has studied the impacts of management on biodiversity in many terrestrial ecosystems, including productive forest systems and grazing land systems.

Melinda Laidlaw received the B.Sc. (Hons) from Griffith University in 1999 and the Ph.D. in ecology from the University of Queensland in 2010.

Since 2005, she has been employed by the Queensland Herbarium where her current projects include the condition assessment and ecological restoration of Queensland's vegetation communities.

Masanobu Shimada (M'97-SM'04) received the B.S. and M.S. degrees in aeronautical engineering from Kyoto University, Japan, in 1977 and 1979, respectively, and the $\mathrm{Ph} . \mathrm{D}$. degree in electrical engineering from the University of Tokyo, Japan, in 1999.

He joined the National Space Development Agency of Japan (NASDA), currently the Japan Aerospace Exploration Agency (JAXA), in 1979. During his time there, he designed a NASDA scatterometer. From 1985 to 1995, he developed data-processing subsystems for optical and SAR data (i.e., MOS-1, SPOT, and JERS-1) at the Earth Observation Center. He served as a visiting scientist in the Jet Propulsion Laboratory, Pasadena, CA, in 1990. Since 1995, he has been assigned duties at the Earth Observation Research Center (EORC), where he serves as the ALOS Science Manager. 